\title{
Physico-chemical study of dew melon peel biochar for chromium attenuation from simulated and actual wastewaters
}

\author{
Mehdi Ahmadi***, Esmaeil Kouhgardi ${ }^{* * *}$, and Bahman Ramavandi****,† \\ *Environmental Technologies Research Center, Ahvaz Jundishapur University of Medical Sciences, Ahvaz, Iran \\ **Department of Environmental Health Engineering, School of Public Health, \\ Ahvaz Jundishapur University of Medical Sciences, Ahvaz, Iran \\ ***Environmental Department, Bushehr Branch, Islamic Azad University, Bushehr, Iran \\ ****Environmental Health Engineering Department, Faculty of Health, \\ Bushehr University of Medical Sciences, Bushehr, Iran \\ (Received 5 June 2015 - accepted 8 May 2016)
}

\begin{abstract}
This work introduces a biochar as novel adsorbent prepared from the dew melon peel by pyrolysis method, and demonstrates its potential for eliminating $\mathrm{Cr}(\mathrm{VI})$ from simulated and actual wastewaters. The dew melon peel biochar (DPB) was characterized by several techniques and methodologies such as, BET, SEM, FTIR, Boehm titration, ultimate analysis, and pHzpc. DPB is a microporous material with the BET specific surface area of $196 \mathrm{~m}^{2} / \mathrm{g}$. The effects of different parameters including $\mathrm{pH}$, amount of adsorbent, $\mathrm{Cr}(\mathrm{VI})$ concentration, and mixing time on the removal of $\mathrm{Cr}(\mathrm{VI})$ from wastewater were studied. Maximum adsorption (98.6\%) was observed at $\mathrm{pH} 6$ and $100 \mathrm{mg} / \mathrm{L}$ metal concentration. The equilibrium adsorption was analyzed by Langmuir, Freundlich, Temkin, and Dubinin-Radushkevich isotherms. Kinetic data were evaluated by pseudo-first order, pseudo-second order, intraparticle diffusion, film diffusion (Boyd), Elovich, and Avrami models. The kinetic data were best fitted to the pseudo-second order model. The Langmuir isotherm model gives the better correlation to predict the adsorption equilibrium, with a maximum adsorption capacity of $198.7 \mathrm{mg} / \mathrm{g}$. The thermodynamic parameters showed that the adsorption of $\mathrm{Cr}(\mathrm{VI})$ was endothermic and spontaneous. Competition between the co-existing ions of $\mathrm{Cl}^{-}, \mathrm{NO}_{3}^{-}, \mathrm{SO}_{4}^{2-}, \mathrm{PO}_{4}^{3-}$, and $\mathrm{HCO}_{3}^{-}$on the adsorption process was studied. The efficacy of DPB was successfully examined by analyzing the removal of $\mathrm{Cr}(\mathrm{VI})$ from two industrial wastewaters. The results indicate that DPB is promising as an effective and economical adsorbent for $\mathrm{Cr}(\mathrm{VI})$ ions removal and could be repeatedly used with no significant loss of adsorption efficiency.

Keywords: Biochar, Dew Melon Peel, Actual Wastewater, Chromium Ion, Industrial Wastewater
\end{abstract}

\section{INTRODUCTION}

Water pollution is a continuing threat to humans and their environment due to the abusive use and uncontrolled release of toxic substances such as chromium. Industrial wastewaters from the electroplating and metallurgy, leather tanning, dye, metal finishing, and textile contain chromium $[1,2]$. Hexavalent chromium species, $\mathrm{Cr}(\mathrm{VI})$, is a highly toxic metal, considered as a priority pollutant because of its carcinogen, mutagen, and teratogen properties $[3,4]$. Therefore, environmental regulations require reducing the $\mathrm{Cr}(\mathrm{VI})$ concentration in wastewater to below $0.1 \mathrm{mg} / \mathrm{L}$ prior to discharge into the environment $[3,5]$. The most common methods used for removal of $\mathrm{Cr}(\mathrm{VI})$ ions from aqueous system include chemical precipitation, ion exchange, membrane processes, electrocoagulation, and electrodialysis [6-8]. But all these methods pose challenges like incomplete $\mathrm{Cr}(\mathrm{VI})$ removal, high operating and maintenance cost, generation of toxic sludge or other waste products that require safe disposal [9]. Therefore, the alternative techniques for removal of $\mathrm{Cr}(\mathrm{VI})$ from wastewater with high efficiency and low cost are urgently

\footnotetext{
${ }^{\dagger}$ To whom correspondence should be addressed.

E-mail: ramavandi_b@yahoo.com, b.ramavandi@bpums.ac.ir

Copyright by The Korean Institute of Chemical Engineers.
}

needed.

Adsorption technique is also used for $\mathrm{Cr}(\mathrm{VI})$ removal. These systems are simple to operate, are not affected by the toxicity of the target pollutant(s) and do not require hazardous chemicals. Furthermore, adsorption facilitates concentrating and then recycling the adsorbate if desired. Table 1 summarizes some of the literature on $\mathrm{Cr}(\mathrm{VI})$ removal by adsorption. As shown, the most common adsorbent is activated carbon, and agricultural waste materials which have a relatively low $\mathrm{Cr}(\mathrm{VI})$ adsorption capacity between 0.15 and $131.5 \mathrm{mg} / \mathrm{g}$. Activated carbon is used for $\mathrm{Cr}(\mathrm{VI})$ removal $[10,11]$, but as it is well-understood the production and regeneration of the activated carbon is very expensive, making it impractical for fullscale applications. Moreover, commercially available activated carbons are still considered expensive due to the use of non-renewable and relatively expensive starting material such as coal. To make the adsorption process attractive and feasible, novel low-cost adsorbents with higher adsorption capacities are required. This has led a growing research interest in the development of new and more effective adsorbents, but at the same time they should be of low cost.

In recent years, agricultural waste materials have been extensively investigated for their ability to eliminate different pollutants from water and wastewater. As reported by Bulut and Tez [25], agricultural materials contain proteins, polysaccharides, and lignin 
Table 1. Summary of recently published literature on $\mathrm{Cr}(\mathrm{VI})$ adsorption by waste-based, commercial, and ion change adsorbent

\begin{tabular}{|c|c|c|c|c|c|c|c|}
\hline Adsorbent & $\begin{array}{l}\text { Opt. } \\
\mathrm{pH}\end{array}$ & $\begin{array}{l}\text { Opt. } \\
\text { adsorbent } \\
\text { dose }(\mathrm{g} / \mathrm{L})\end{array}$ & $\begin{array}{l}\text { Opt. } \\
\text { contact } \\
\text { time (min) }\end{array}$ & Fitted kinetic model & $\begin{array}{l}\text { Fitted isotherm } \\
\text { model }\end{array}$ & $\begin{array}{l}\text { Adsorption } \\
\text { capacity } \\
(\mathrm{mg} / \mathrm{g})\end{array}$ & Ref. \\
\hline Surfactant-modified zeolite & 7 & 1 & 100 & Pseudo-second order & Langmuir & 4.4 & {$[1]$} \\
\hline Pistachio hull waste & 2 & 5 & 20 & Pseudo-second order & Langmuir & 116.3 & {$[3]$} \\
\hline Acorn of Quercus ithaburensis & 2 & 10 & 60 & Pseudo-second order & $\begin{array}{l}\text { Langmuir and } \\
\text { Freundlich }\end{array}$ & 31.5 & [7] \\
\hline Banana peel & 2 & 10 & 30 & Pseudo first order & Langmuir & 131.56 & [12] \\
\hline Beech sawdust & 1 & 10 & 80 & - & $\begin{array}{l}\text { Langmuir and } \\
\text { Freundlich }\end{array}$ & 16.1 & [13] \\
\hline Rice husks & 3 & - & 1440 & - & Freundlich & 0.6 & {$[14]$} \\
\hline Saw dust & 3 & - & 1440 & - & Freundlich & 1.5 & [14] \\
\hline Coir pith & 3 & - & 1440 & - & Freundlich & 0.2 & [14] \\
\hline Rice bran & $1.5-2$ & 0.2 & 60 & Pseudo-second order & Freundlich & 0.15 & {$[15]$} \\
\hline Walnut shell & 4 & 2 & 50 & Pseudo first order & Freundlich & 2.3 & [16] \\
\hline Tamarindus indica seed & 4 & 2 & 50 & Pseudo first order & Freundlich & 98.1 & [16] \\
\hline Ground nut shell & 4 & 2 & 50 & Pseudo first order & Langmuir & 5.9 & [16] \\
\hline Almond shell & 2 & 2 & 50 & Pseudo first order & Freundlich & 22.1 & [16] \\
\hline Palm flower & 7 & 4.5 & 60 & Pseudo-second order & All models & 4.9 & {$[17]$} \\
\hline Cystoseira indica & 3 & 1.5 & 120 & Pseudo-second order & $\begin{array}{l}\text { Dubinin- } \\
\text { Radushkevich }\end{array}$ & $17.8-22.7$ & [18] \\
\hline Ocimum americanum $L$. seed pods & 1.5 & 4 & 30 & Pseudo-second order & Langmuir & 83.33 & [19] \\
\hline Grape waste & 4 & 10 & 20 & - & Langmuir & 99.3 & [20] \\
\hline Mucor hiemalis & 2 & 8 & 240 & Pseudo-second order & Langmuir & 53.5 & [21] \\
\hline Tamarind seeds & $1-3$ & 20 & 300 & Pseudo-second order & Langmuir & 29.7 & {$[22]$} \\
\hline Magnetic natural zeolite-polypyrrole & 2 & 1.5 & $24 \mathrm{~h}$ & Pseudo-second order & Langmuir & 344.83 & [23] \\
\hline Activated carbon & 5 & 10 & $10 \mathrm{~h}$ & Pseudo-second order & Langmuir & 102.88 & {$[24]$} \\
\hline
\end{tabular}

which are associated with functional groups responsible for metal ion adsorption. They are locally available in abundance, and the presence of large amount of surface functional groups make various agricultural wastes suitable options for expensive synthetic adsorbents [26]. Different agro-wastes like orange wastes [27], olive pomace [28], rice milling by-products [29], Pinus sylvestris sawdust [30], and ash gourd [31] as well as olive stone [32] have been studied for this purpose.

One agricultural waste that is widely accessible in the world is the dew melon peel. China produces about $50 \%$ of the worlds dew melon by weight. Iran and Turkey are the next largest dew melonproducing countries, with the U.S. and Spain rounding out the top five. Europe, Central America, and Africa are also important world production centers for dew melon [33,34]. In Japan, dew melon is usually grown in greenhouses. Approximately 500000 metric tons of dew melon is generated annually in Iran. Thus, an abundant source of material is available at low-cost. Furthermore, the use of agricultural wastes as adsorbents is an eco-friendly technique that could help to waste management. Our aim of was to (a) investigate the physicochemical properties of biochar produced under a given pyrolysis temperature using dew melon peel as the basic material, (b) study the kinetics, isotherms, and thermodynamic of $\mathrm{Cr}(\mathrm{VI})$ adsorption onto the DPB to remove $\mathrm{Cr}(\mathrm{VI})$ under varying conditions, (c) optimize various variables including wastewater $\mathrm{pH}$, adsorbent dose, $\mathrm{Cr}(\mathrm{VI})$ concentration, and mixing time on $\mathrm{Cr}(\mathrm{VI})$ adsorption, (d) evaluate the reusability of DPB, (e) determine the impact of DPB on conductivity and turbidity of treated solutions, and ( $f$ ) assess the treatment of two actual wastewaters by DPB. Purposes of (a-e) were carried out in a simulated wastewater sample (Cr(VI)-spiked tap water). To the best of the authors' knowledge, no publicly funded research has yet investigated the use of dew melon peel biochar (DPB) in applications such as water and wastewater treatment.

\section{MATERIALS AND METHODS}

\section{Materials}

Potassium dichromate $\left(\mathrm{K}_{2} \mathrm{Cr}_{2} \mathrm{O}_{7}\right)$ with purity more than $99 \%$ was used to provide synthetic wastewater. The solution $\mathrm{pH}$ was regulated to the determined value using a $0.1 \mathrm{~N} \mathrm{NaOH}$ or $\mathrm{HCl}$ solution. The chemicals and reagents used in this study were of analytical grade and supplied from Merck Co. Double distilled water was applied for preparation of the required reagent.

\section{Preparation of the Adsorbent}

The dew melon peel mass samples were collected from a local farm in the Bushehr province, Iran, the location of the major dew melon harvest in the region. The dew melon peel were dried during four consecutive days and then chopped to small pieces. After that, the dew melon peel was pyrolyzed using a closed system, which was synthesized from stainless steel and had a height of $22 \mathrm{~cm}$ and 
diameter of $7 \mathrm{~cm}$. The pyrolysis process was performed for $4 \mathrm{~h}$ to produce the dew melon peel biochar (DPB) at a given temperature $\left(450^{\circ} \mathrm{C}\right)$ under oxygen-limited conditions and nitrogen gas. To remove ashes or other impurities from the surface of the sample, the sample was washed three times with double distilled water and then dried at $105^{\circ} \mathrm{C}$ for $24 \mathrm{~h}$. Finally, the biochar samples were powdered in a hammer micromill (Parsazma model, Iran) and sieved to a mesh size of 230 for further analysis.

\section{Parameters Optimization}

Adsorption tests were optimized out at the given $\mathrm{pH}$ level, mixing time and DPB dosage value using the necessary DPB in a 200 $\mathrm{mL}$ stoppered conical flask containing $50 \mathrm{~mL}$ of test solution. Initial solutions with different concentration of $\mathrm{Cr}(\mathrm{VI})$ were prepared by proper dilution from stock $1,000 \mathrm{mg} / \mathrm{L} \mathrm{Cr}(\mathrm{VI})$ standards.

Desired amount of the adsorbent was then added and contents in the flask were shaken for the known mixing time ( $40 \mathrm{~min}$ ) in a shaker-incubator (Parsazma model, Iran) at $120 \mathrm{rpm}$. The time required for reaching the equilibrium condition was calculated by drawing samples at regular intervals of time till equilibrium was reached. Thirty $\mathrm{mL}$ aliquots were filtered through $0.45 \mu \mathrm{m}$ filters at various time intervals. The adsorption efficiency was calculated as follows:

$$
\mathrm{R}(\%)=\frac{\mathrm{C}_{0}-\mathrm{C}_{t}}{\mathrm{C}_{0}} \times 100
$$

where $\mathrm{C}_{0}$ is the initial chromium concentration $(\mathrm{mg} / \mathrm{L}), \mathrm{C}_{t}$ is the residual concentration of $\mathrm{Cr}(\mathrm{VI})$ at a given time $(\mathrm{mg} / \mathrm{L})$.

Adsorption isotherms were obtained by shaking for the appropriate time interval, different initial concentrations of solution of the corresponding ion with a fixed mass of adsorbent. Then the amount of chromium remaining in the solution was determined. The amount of adsorbed $\mathrm{Cr}(\mathrm{VI})$ at equilibrium was calculated from a simple mass balance equation as follows:

$$
\mathrm{q}_{e}=\frac{\mathrm{V}\left(\mathrm{C}_{0}-\mathrm{C}_{e}\right)}{\mathrm{m}}
$$

where $\mathrm{V}$ is the solution volume $(\mathrm{L})$ and $\mathrm{m}$ is mass of the DPB (g).

\section{Adsorption Isotherm}

The $\mathrm{Cr}(\mathrm{VI})$ adsorption isotherm was determined using batch experiments at the initial $\mathrm{pH}$ value of 4.0 and wastewater temperature of $24^{\circ} \mathrm{C}$. The initial $\mathrm{Cr}(\mathrm{VI})$ concentrations were 50, 100, 150, 200, 250, 300, and $400 \mathrm{mg} / \mathrm{L}$. The total mixing time was set to $8 \mathrm{~h}$. The $\mathrm{Cr}(\mathrm{VI})$ concentrations of the equilibrium solutions $\left(\mathrm{C}_{e}\right)$ were measured for isotherm models listed in Table 2. Apart from correlation coefficient $\left(\mathrm{R}^{2}\right)$, the validity of the adsorption isotherm and its goodness-of-fit was evaluated with the root mean square error (RMSE), which can be defined according to Eq. (3).

$$
\mathrm{RMSE}=\sqrt{\frac{1}{\mathrm{~N}} \sum_{i=1}^{N}\left(\mathrm{q}_{e i}^{e x p}-\mathrm{q}_{e i}^{c a l}\right)^{2}}
$$

where $\mathrm{q}_{e i}^{e x p}$ is the observation from the batch experiment $\mathrm{i}, \mathrm{q}_{e i}^{c a l}$ is the estimated from the isotherm for corresponding $\mathrm{q}_{e i}^{\exp }$, and $\mathrm{N}$ is the number of measurements made. The smaller RMSE values reveal more accurate estimation of $\mathrm{q}_{e}$ value [1].

\section{Adsorption Kinetics}

A kinetics study was carried at out wastewater temperature of $24^{\circ} \mathrm{C}$. Simulated wastewater containing different concentrations of

Table 2. Non-linear forms of isotherm and kinetic models and thermodynamic assessment [36,37]

\begin{tabular}{lll}
\hline \hline Models & Name & Non-linear forms \\
\hline Isotherm & Langmuir & $\mathrm{q}_{e}=\frac{\mathrm{Q}_{m} \mathrm{k}_{L} \mathrm{C}_{e}}{1+\mathrm{k}_{L} \mathrm{C}_{e}} \mathrm{R}_{L}=\frac{1}{1+\mathrm{k}_{L} \mathrm{C}_{e}}$ \\
& Freundlich & $\mathrm{q}_{e}=\mathrm{k}_{F} \mathrm{C}_{e}^{1 / n}$ \\
& Temkin & $\mathrm{q}_{e}=\frac{\mathrm{RT}}{\mathrm{b}_{T}} \ln \left(\mathrm{k}_{T} \mathrm{C}_{e}\right) ; \mathrm{B}_{1}=\mathrm{RT} / \mathrm{b}_{1}$ \\
& Dubinin-Radushkevich (D-R) & $\ln _{e}=\ln \mathrm{q}_{m}-\mathrm{K}_{D R} \varepsilon^{2} ; \mathrm{E}=\left(2 \mathrm{~K}_{D R}\right)^{-0.5}$ \\
& Pseudo-first order & $\mathrm{q}_{t}=\mathrm{q}_{e}\left[1-\exp \left(-\mathrm{k}_{1} \mathrm{t}\right)\right]$ \\
& Pseudo-second order & $\mathrm{q}_{t}=\frac{\mathrm{k}_{2} \mathrm{q}_{e}^{2} \mathrm{t}}{1+\mathrm{k}_{2} \mathrm{q}_{e} \mathrm{t}}$ \\
& Elovich & $\mathrm{q}_{t}=\frac{1}{\beta} \ln (1+\alpha \beta \mathrm{t})$ \\
& Avrami & $\mathrm{q}_{t}=\mathrm{q}_{e}\left[1-\exp \left(-\mathrm{k}_{A t} \mathrm{t}\right) \mathrm{n}_{A V}\right]$ \\
& Intraparticle diffusion & $\mathrm{q}_{t}=\mathrm{k}_{i d} \sqrt{\mathrm{t}}+\mathrm{C}_{i}$ \\
& Film diffusion (Boyd) & $\mathrm{B}_{t}=-\ln \left(1-\frac{\mathrm{q}_{t}}{\mathrm{q}_{e}}\right)-0.4977$ \\
& Gibbs free energy and sticking probability & $\Delta \mathrm{G}^{o}=-\mathrm{RT} \ln \mathrm{K}^{o} ; \Delta \mathrm{G}^{o}=\Delta \mathrm{H}^{o}-\mathrm{T} \Delta \mathrm{S}^{o}, \mathrm{SP} *=(1-\mathrm{B}) \exp -($ Ea/RT) \\
\hline
\end{tabular}

$\mathrm{Q}_{m}=$ maximum adsorption capacity, $\mathrm{k}_{L}=$ Langmuir constant, $\mathrm{R}_{L}=$ separation factor; $\mathrm{k}_{F}$ and $\mathrm{n}_{F}=$ Freundlich constants; $\mathrm{R}=$ universal gas constant, $\mathrm{T}=$ absolute temperature in Kelvin $(298 \mathrm{~K})$, and $\mathrm{k}_{T}$ and $\mathrm{b}_{T}=$ Temkin constants; $\mathrm{K}_{D R}=\mathrm{D}-\mathrm{R}$ constant $\left(\mathrm{mol}^{2} / \mathrm{kJ}^{2}\right), \varepsilon=$ Polanyi potential $(\mathrm{J} /$ $\mathrm{mol}), \mathrm{E}=$ adsorption free energy $(\mathrm{kJ} / \mathrm{mol}), \mathrm{k}_{1}=$ rate constant of pseudo-first order model, $\mathrm{k}_{2}=$ rate constant of pseudo-second order model, $\mathrm{k}_{A V}$ and $\mathrm{n}_{A V}=$ Avrami constants, $\alpha$ and $\beta=$ Elovich constants, $\mathrm{k}_{i d}$ and $\mathrm{C}_{i}=$ intraparticle diffusion constants, $\mathrm{B}_{t}=$ Boyd constant, $\mathrm{q}_{t}=$ adsorbed amount at any time, $\mathrm{q}_{e}=$ adsorbed amount at equilibrium, $\Delta \mathrm{G}^{o}=\mathrm{Gibbs}$ free energy change, $\Delta \mathrm{H}^{o}=$ enthalpy change, $\Delta \mathrm{S}^{\circ}=$ entropy change, $\mathrm{K}^{\circ}=$ thermodynamic equilibrium constant, $\mathrm{SP}^{*}=$ sticking probability, and $\mathrm{B}=$ surface coverage 
50,100 , and $150 \mathrm{mg} / \mathrm{L}$ was used. The $\mathrm{pH}$ of wastewater was adjusted to 4.0. Approximately $30 \mathrm{~mL}$ aliquots were taken from the solution at different time intervals for the residual $\mathrm{Cr}(\mathrm{VI})$ concentration testing. The quantity of $\mathrm{Cr}(\mathrm{VI})$ adsorbed onto the DPB at time t, $\mathrm{q}_{t}$ (mg/g), was calculated by Eq. (4):

$$
\mathrm{q}_{t}=\frac{\mathrm{V}\left(\mathrm{C}_{0}-\mathrm{C}_{t}\right)}{\mathrm{m}}
$$

where $C_{t}(\mathrm{mg} / \mathrm{L})$ is the concentration at time $\mathrm{t}$.

Six kinetic models (Table 2) were employed to fit the experimental data. In kinetics studies apart from the correlation coefficient $\left(\mathrm{R}^{2}\right)$, the validity of kinetic models was measured by the normalized standard deviation (NSD), which can be defined as:

$$
\mathrm{NSD}=100 \sqrt{\frac{1}{\mathrm{~N}-1} \sum_{i=1}^{N}\left[\frac{\left(\mathrm{q}_{t}^{\exp }-\mathrm{q}_{t}^{c a l}\right)}{\mathrm{q}_{t}^{\exp }}\right]^{2}}
$$

where $\mathrm{q}_{t}^{\text {exp }}$ and $\mathrm{q}_{t}^{\text {cal }}(\mathrm{mg} / \mathrm{g})$ are experimental and calculated $\mathrm{Cr}(\mathrm{VI})$ adsorbed on DPB at time $t$. The smaller NSD values indicate more accurate estimation of $\mathrm{q}_{t}$ values [35].

\section{Tests of Co-existing Anion}

To study the effects of co-existing and/or competing anions (chloride, nitrate, sulfate, bicarbonate, and phosphate) on $\mathrm{Cr}(\mathrm{VI})$ adsorption, we used a fixed initial competing anion concentration (2.5 $\mathrm{mmol} / \mathrm{L}$ ) and initial $\mathrm{Cr}(\mathrm{VI})$ concentrations of $100 \mathrm{mg} / \mathrm{L}$ (other conditions: wastewater $\mathrm{pH} 4.0$, wastewater temperature $24^{\circ} \mathrm{C}$, and mixing time $40 \mathrm{~min}$ ).

\section{Reuse Tests}

To do reusability tests, the adsorbent of $\mathrm{Cr}(\mathrm{VI})$ was regenerated for four consecutive cycles by using sodium hydroxide $(1 \mathrm{~N} \mathrm{HCl})$ solution. The regenerated DPB was then subjected to chromium adsorption under the experimental conditions of $\mathrm{pH} 4$, initial $\mathrm{Cr}(\mathrm{VI})$ concentration of $100 \mathrm{mg} / \mathrm{L}$, mixing time $40 \mathrm{~min}$, and wastewater temperature $24^{\circ} \mathrm{C}$.

\section{Adsorbent Effect on Conductivity (EC) and Turbidity}

For the EC test, $2 \mathrm{~g} / \mathrm{L}$ of the DPB was introduced into $200 \mathrm{~mL}$ simulated wastewater at $\mathrm{pH} 4.0$ and shaken at $120 \mathrm{rpm}$. At predetermined time intervals, the sample was taken for conductivity and turbidity measurements (Jenway, Model 4520).

\section{Simulated and Actual Wastewater Treatment}

A tap water sample $\left(\mathrm{NO}_{3}^{-}: 11 \mathrm{mg} / \mathrm{L}, \mathrm{PO}_{4}^{3-}: 1.8 \mathrm{mg} / \mathrm{L}, \mathrm{SO}_{4}^{2-}: 8\right.$ $\mathrm{mg} / \mathrm{L}$, TDS: $127 \mathrm{mg} / \mathrm{L}$, and $\mathrm{pH}$ 7.01) was spiked with $\mathrm{Cr}(\mathrm{VI})$ to $50-$ $150 \mathrm{mg} / \mathrm{L}$ as a simulated wastewater containing $\mathrm{Cr}(\mathrm{VI})$.

To examine the practical utility of DPB for $\mathrm{Cr}(\mathrm{VI})$ removal from actual wastewaters, an experiment was carried out to remove $\mathrm{Cr}(\mathrm{VI})$ from the effluent of two local industrial plants, electroplating and tannery. No properties of wastewaters were adjusted and spiked to desired value. The samples were delivered to the laboratory within $2 \mathrm{~h}$ of being taken and tested within 1 day. The samples were kept at $4{ }^{\circ} \mathrm{C}$ without adding any chemicals. The wastewaters, consisting of both organic and inorganic substances, were acidic $(\mathrm{pH}<5.6)$. In this section, the experiment was carried out under the optimized conditions, DPB concentrations of $2 \mathrm{~g} / \mathrm{L}$, temperature $24^{\circ} \mathrm{C}$, stirring speed $120 \mathrm{rpm}$, and mixing time $40 \mathrm{~min}$.

\section{Analytical Methods and Characteristics of DPB}

All analytical measurements were taken according to methods of the American Public Health Association [38]. Cr(VI) and Cr(III) were measured using 1,5-diphenylcarbazide as described in the standard methods [38]. To Cr(III) determination, 1,5-diphenylcarbazide method was done in presence and absence of potassium permanganate $\left(\mathrm{KMnO}_{4}\right)$ as oxidant [39]. $\mathrm{Cr}$ (III) was estimated as the difference between $\mathrm{Cr}_{\text {total }}[\mathrm{Cr}(\mathrm{VI})+\mathrm{Cr}(\mathrm{III})]$ (determined in presence of $\mathrm{KMnO}_{4}$ ), and $\mathrm{Cr}(\mathrm{VI})$ (determined in absence of $\mathrm{KMnO}_{4}$ ). The amount of total organic carbon (TOC) was determined by using a Shimadzu TOC-5000 Analyzer (Shimadzu Co., Japan). All tests were done in triplicate and data presented as averages.

The elements of C, H, S, and $\mathrm{N}$ in the structure of the DPB were analyzed by using a Vario III Elemental Analyzer. The oxygen value was estimated by the direct method (EuroVector apparatus, model 3018). The value of basic and acidic groups on carbon surface was measured by titration with $\mathrm{HCl}$ and $\mathrm{NaOH}$, respectively, according to the method of Boehm. The surface morphology of the DPB and $\mathrm{Cr}(\mathrm{VI})$-loaded DPB was also determined by scanning electron microscope (SEM) (Hitachi S-4800). The BET surface area, pore volume, and average pore diameter were determined by $\mathrm{N}_{2-}$ BET method using Belsorp Mini 2 (see Table 3). The $\mathrm{pH}$ of zero charge point $\left(\mathrm{pH}_{z p c}\right)$ was calculated by mixing $1 \mathrm{~g}$ of DPB with $20 \mathrm{~cm}^{3}$ of $\mathrm{CO}_{2}$-free double distillated water, according to the $\mathrm{pH}$ drift procedure [35]. The $\mathrm{pH}$ of solutions was determined with a pH meter (METLER TOLEDO FE20).

\begin{tabular}{|c|c|c|}
\hline Property & Parameter & Value \\
\hline \multirow[t]{8}{*}{ Physical } & pHzpc (pH unit) & 8.3 \\
\hline & $\operatorname{BET}\left(\mathrm{m}^{2} / \mathrm{g}\right)$ & 196 \\
\hline & Total pore volume $\left(\mathrm{cm}^{3} / \mathrm{g}\right)$ & 0.0013 \\
\hline & Average pore diameter $(\mathrm{nm})$ & 0.71 \\
\hline & Bulk density $\left(\mathrm{g} / \mathrm{cm}^{3}\right)$ & 0.421 \\
\hline & Particle size (mm) & $<0.063$ \\
\hline & $\mathrm{C}$ constant of BET & 423 \\
\hline & Mesh & 230 \\
\hline \multirow[t]{18}{*}{ Chemical } & Biochar yield (\%) & 45.2 \\
\hline & Ash (\%) & 14.23 \\
\hline & Water (\%) & 2.1 \\
\hline & Fatty compounds (\%) & Negligible \\
\hline & \multicolumn{2}{|c|}{ Boehm functional groups $(\mathrm{mmol} / \mathrm{g})$} \\
\hline & Basic & 1.22 \\
\hline & Acidic & 0.25 \\
\hline & \multicolumn{2}{|c|}{ Ultimate analysis (wt\%, dry basis) } \\
\hline & $\mathrm{C}$ & 83.2 \\
\hline & $\mathrm{H}$ & 3.12 \\
\hline & $\mathrm{N}$ & 0.2 \\
\hline & $\mathrm{S}$ & No detected \\
\hline & $\mathrm{O}$ & 13.47 \\
\hline & $(\mathrm{O}+\mathrm{N}) / \mathrm{C}$ & 0.164 \\
\hline & $\mathrm{H} / \mathrm{C}$ (mass/mass) & 0.037 \\
\hline & $\mathrm{O} / \mathrm{C}$ (mass/mass) & 0.16 \\
\hline & $\mathrm{H} / \mathrm{C}$ (mole/mole) & 0.18 \\
\hline & $\mathrm{O} / \mathrm{C}$ (mole/mole) & 0.003 \\
\hline
\end{tabular}

Table 3. Properties of DPB used in the tests 


\section{RESULTS AND DISCUSSION}

\section{Physical and Chemical Characteristics of DPB}

The DPB particles used in this study had a BET multipoint surface area of $196 \mathrm{~m}^{2} / \mathrm{g}$ and a total pore volume at $0.9925 \mathrm{P} / \mathrm{P}_{0}$ of 0.0013 $\mathrm{cm}^{3} / \mathrm{g}$. The BET C constant of DPB was 423 , indicating the high affinity of DPB for adsorbing of $\mathrm{Cr}(\mathrm{VI})$ ions. According to the calculations, the average pore size was $0.71 \mathrm{~nm}$, confirming that DPB was a microporous adsorbent. Because the specific surface area of DPB is relatively low, functional groups likely play a greater role than particle surface area [37] in adsorbing chromium ions from wastewaters.

The data of the chemical characteristics (elemental analysis, water and fat contents) of the DPB are given in Table 3. The DPB obtained contained $2.1 \%$ humidity and negligible amount of fatty compounds. The low amount of humidity will lead to easy housekeeping of the adsorbent. On the other hand, acid-base properties of DPB were characterized by a mechanistic model denoting that this adsorbent is characterized by a main kind of active site (carboxylic groups) [40].

The elemental compositions and ratios in the fresh DPB sample are shown in Table 3. The high carbon (C) content of the produced biochar on the contrary, the amount of nitrogen $(\mathrm{N})$, hydrogen $(\mathrm{H})$ and oxygen $(\mathrm{O})$ contained in the biochar was low at the pyrolysis temperature. Very low or insignificant amounts of sulfur (S) were observed. This is due to increased oxidation at the pyrolysis temperature, and reflects the conclusion drawn by Schmidt and Noack [41] on the characteristics of black carbon. They [41] claimed that biochar sample represents a continuum from partially charred organic material to graphite/soot particles, with no clear boundary. Consequently, this continuum can be extended to the compositional characteristics associated with an increasing degree of oxidation.

Compared to findings by another researcher [42], the very low $\mathrm{H} / \mathrm{C}$ and $\mathrm{O} / \mathrm{C}$ ratios obtained for the biochar indicated that carbon in this material is predominantly unsaturated; the biochar formed at $450^{\circ} \mathrm{C}$ can be represented by the generic formula $\left(\mathrm{C}_{1} \mathrm{H}_{0.2} \mathrm{O}_{0.003}\right)$, such that most $\mathrm{C}$ atoms are directly bonded to other carbons. Moreover, there is very little oxygen left in the biochar sample formed at compared to carbon; appreciable quantities of $\mathrm{H}$ persist in the temperature chars. This residual hydrogen is thought to be aromatic. The low ratio of the $(\mathrm{O}+\mathrm{N}) / \mathrm{C}$ indicates that biochar samples contain polar functional groups, reaffirming the aromaticity and polarity of biochar produced at the temperature of $450^{\circ} \mathrm{C}$. These results are in agreement with those obtained by Al-Wabel et al. [43].

To acquire information on Cr-DPB interactions, Fourier-transform infrared (FTIR) spectroscopy has proven an influential means to get structural and bonding information. The FTIR spectra of DPB before and after $\mathrm{Cr}(\mathrm{VI})$ adsorption following $8 \mathrm{~h}$ of contact with $\mathrm{Cr}(\mathrm{VI})$ solution were taken in the range of $4,000-400 \mathrm{~cm}^{-1}$ (Fig. 1). The spectrum of the fresh DPB exhibits a broad absorption band around $3,745 \mathrm{~cm}^{-1}$ corresponding to $\mathrm{O}-\mathrm{H}$ stretching vibrations of the hydroxyl groups and N-H stretching vibration of the amide groups [44] is shifted to $3,759 \mathrm{~cm}^{-1}$ after adsorption of $\mathrm{Cr}(\mathrm{VI})$ ions, which may be ascribed to the complexation of $-\mathrm{OH}$ and amide groups with $\mathrm{Cr}(\mathrm{VI})$ ions. The absorption band appearing at 1,648 $\mathrm{cm}^{-1}$ has shifted to $1,657 \mathrm{~cm}^{-1}$, which may be attributed to the com-

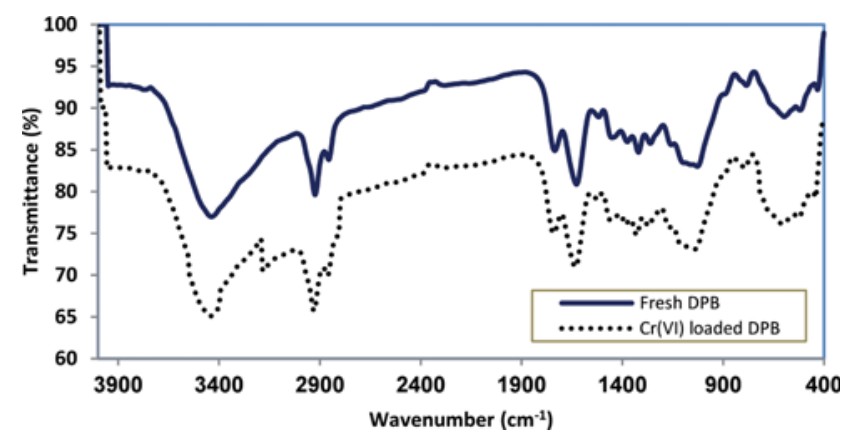

Fig. 1. FTIR spectra of fresh and Cr(VI) ions loaded DPB.
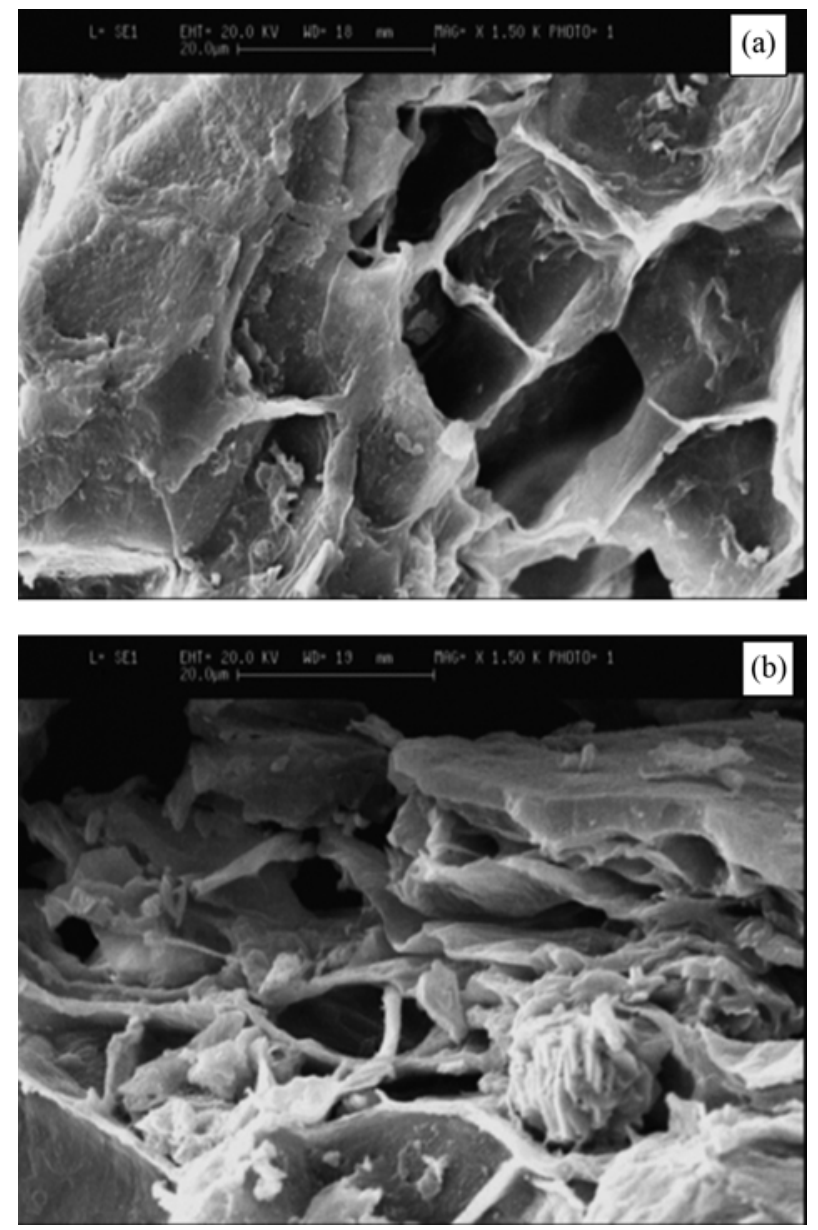

Fig. 2. Scanning electron micrograph of DPB (a) before and (b) after $\mathrm{Cr}(\mathrm{VI})$ adsorption.

plexation of carboxylic group with $\mathrm{Cr}(\mathrm{VI})$ ions [45,46]. The peak observed at $1,104 \mathrm{~cm}^{-1}$ shifted to $1,109 \mathrm{~cm}^{-1}$ which may also be attributed to the interaction of amino group with $\mathrm{Cr}(\mathrm{VI})$ ions.

The SEM images of the DPB before and after chromium adsorption are presented in Fig. 2. The SEM images clearly show that the reaction of $\mathrm{Cr}(\mathrm{VI})$ ions with $\mathrm{Cr}(\mathrm{VI})$ - DPB made the surface of $\mathrm{Cr}(\mathrm{VI})$ - DPB less rough and protrusions. To further investigate the surface characteristic of the DPB before and after $\mathrm{Cr}(\mathrm{VI})$ ions adsorption, an energy dispersive X-ray (EDX) analysis was also done and the results are depicted in Fig. 3(a) and (b). Fig. 3(a) 

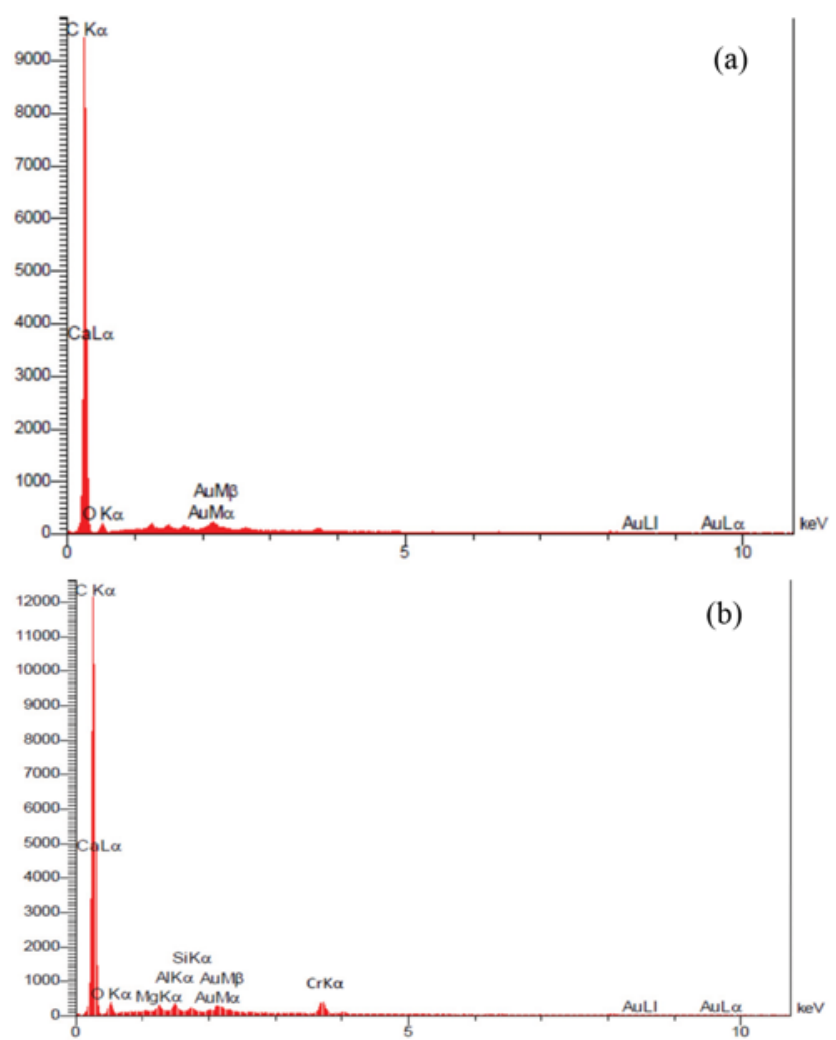

Fig. 3. Energy dispersive X-ray (EDX) analysis of $\mathrm{Cr}(\mathrm{VI})-\mathrm{DPB}$ : (a) Before adsorption and (b) after adsorption.

does not show the characteristic signal of $\mathrm{Cr}(\mathrm{VI})$, which, however, is clearly observed in the Fig. 3(b).

\section{Impact of Solution $\mathbf{p H}$}

The $\mathrm{pH}$ value of the medium is a significant factor in the adsorption process and governs the speciation of metals and also the dissociation of active functional sites on the adsorbent [47]. Hence, metal adsorption is critically linked with solution $\mathrm{pH}$. Not only do different metals show different $\mathrm{pH}$ optima for their adsorption, but may also vary from one kind of adsorbent to another. Generally, metal adsorption involves complex mechanisms of ion exchange, chelation, physical adsorption, and ion entrapment in spaces of

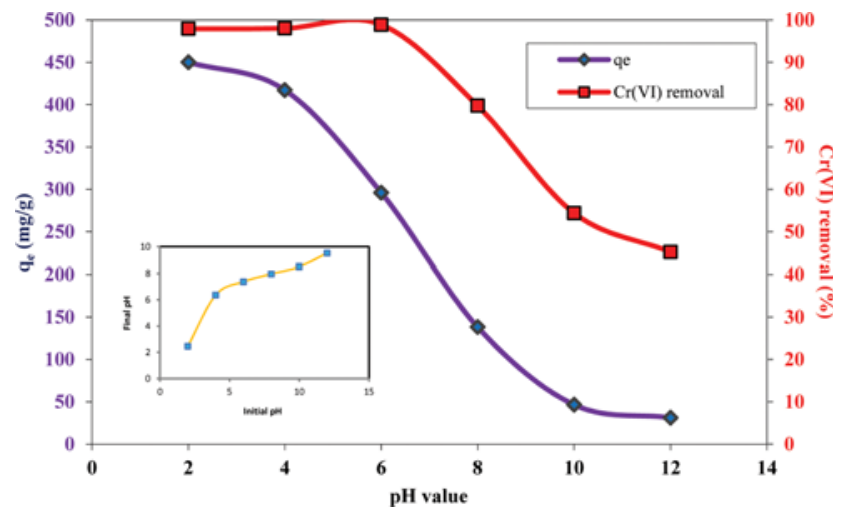

Fig. 4. Effects of initial $\mathrm{pH}$ on adsorption capacity and $\mathrm{Cr}(\mathrm{VI})$ removal. the cell structural network of an adsorbent [35]. The effect of solution $\mathrm{pH}$ on the adsorption of $\mathrm{Cr}(\mathrm{VI})$ by $\mathrm{DPB}$ was evaluated in the range of 2-12; the results are depicted in Fig. 4. As illustrated in Fig. 4, when the $\mathrm{pH}$ level of the solution was raised from 2 to 6 , the $\mathrm{Cr}(\mathrm{VI})$ removal efficiency increased from $97.94 \%$ to $98.9 \%$, and further increasing in solution $\mathrm{pH}$ led to a notable decrease in removal efficiency. The maximum $\mathrm{Cr}(\mathrm{VI})$ adsorption was found at $\mathrm{pH}$ 6. Attaining the maximum $\mathrm{Cr}(\mathrm{VI})$ adsorption at $\mathrm{pH} 6$ is of great importance from application point of view, since the $\mathrm{pH}$ of most natural water and wastewater is usually neutral. This overcomes the necessity of more $\mathrm{pH}$ manipulation for maximizing the adsorption, which in turn makes the treatment more cost-effective. Therefore, $\mathrm{pH} 6$ was selected for the rest of experiments throughout the study. Peak Cr(VI) adsorption at $\mathrm{pH} 6$ can be explained by considering the fact that the $\mathrm{pH}$ of the solution influences both the surface charge of the DPB and the dominant species of chromium in the solution. According to the literature [10], various $\mathrm{Cr}(\mathrm{VI})$ species such as $\mathrm{HCrO}_{4}^{-}, \mathrm{CrO}_{4}^{2-}$ and $\mathrm{Cr}_{2} \mathrm{O}_{7}^{2-}$ are in solution as a function of $\mathrm{pH}$. Within the acidic $\mathrm{pH}$ range, $\mathrm{HCrO}_{4}^{-}$and $\mathrm{Cr}_{2} \mathrm{O}_{7}^{2-}$ are predominant, whereas at basic $\mathrm{pH}$, the dominant species is $\mathrm{CrO}_{4}^{2-}$. As all $\mathrm{Cr}(\mathrm{VI})$ species are anionic, a decrease in $\mathrm{pH}$ causes the adsorbent surface to charge positively due to the protonation of the active groups, creating a strong attraction for the negatively charged $\mathrm{Cr}(\mathrm{VI})$ ions. However, as the $\mathrm{pH}$ increases, the $\mathrm{H}^{+}$concentration decreases and the surface charge of the adsorbent becomes negative, which would prevent the retention of the chromium species. This would justify a decrease in $\mathrm{Cr}(\mathrm{VI})$ adsorption as the $\mathrm{pH}$ increases in the media, a conclusion that numerous researchers reached in their studies $[1,10,13]$.

It is obvious from Fig. 4 that at $\mathrm{pH}$ values higher than $7, \mathrm{Cr}(\mathrm{VI})$ removal by DPB is not satisfactory. The lower adsorption capacity at $\mathrm{pH}>7$ can be explained by increasing competition with the $\mathrm{OH}^{-}$ ions and by the presence of $\mathrm{CrO}_{4}^{2-}$ species which have a different charge to $\mathrm{Cr}$ - atoms ratio than the $\mathrm{Cr}_{2} \mathrm{O}_{7}^{2-}$ and $\mathrm{HCrO}_{4}^{-}$species presence at acidic $\mathrm{pH}$. As reported by others [3], the effect of specific $\mathrm{pH}$ level of a solution can be attributed to the electrostatic interactions between the $\mathrm{Cr}(\mathrm{VI})$ species present in the solution and the DPB surface, and also to the specific selection of an DPB for the $\mathrm{Cr}(\mathrm{VI})$ species. The surface charge of an adsorbent is indicated by its $\mathrm{pH}_{z p c}$. The $\mathrm{pH}_{z p c}$ of the DPB was found to be 8.3, implying that the surface of the DPB is uncharged in an aqueous solution of $\mathrm{pH}$ 8.3, positively charged at $\mathrm{pH}<8.3$ and negatively charged at $\mathrm{pH}>8.3$. At $\mathrm{pH}$ values higher than 8.3 , the negatively charged surface of the DPB repels the negatively charged chromate ions, whereas, at lower $\mathrm{pH}$, it attracts and binds them. Therefore, the maximum adsorption of DPB was recorded when the $\mathrm{pH}$ was around 4. According to Table 1 , most researchers have similarly reported attaining maximum $\mathrm{Cr}(\mathrm{VI})$ adsorption onto different adsorbents in the acidic $\mathrm{pH}$ range.

To verify the $\mathrm{pH}$ variation during the adsorption process, the initial $\mathrm{pH}$ versus the final $\mathrm{pH}$ is also presented in the inset of Fig. 4. The final $\mathrm{pH}$ remains almost unchanged when the solution is strongly acidic ( $\mathrm{pH}$ 2). In very acidic solution a removal of protons occurs due to the presence of functional groups with acid-basic properties in the DPB and the reduction of $\mathrm{Cr}$ (VI) to $\mathrm{Cr}$ (III) that also consumes protons. However, an increase of final solution $\mathrm{pH}$ 
is not appreciated, probably because in a strongly acidic solution, the proton concentration is very high and this effect is not notable. At initial $\mathrm{pH}$ values of 4 and 6 an increase in $\mathrm{pH}$ during the experiment is clearly observed, which could be described by the removal of protons of the solution by the adsorbent. The decreasing in initial $\mathrm{pH}$ values $(8,10$, and 12) may be due to exchange of $\mathrm{Cr}(\mathrm{VI})$ with $\mathrm{H}^{+}$of hydrogenated functional groups, and consequently release the $\mathrm{H}^{+}$into solution. However, at these $\mathrm{pH}$ values the reduction of $\mathrm{Cr}(\mathrm{VI})$ is practically meaningless. These results agree with those obtained by numerous researchers, indicating that, although the protonation of the adsorbent and the reduction of $\mathrm{Cr}(\mathrm{VI})$ are the main causes for the $\mathrm{pH}$ alteration in the solution, the various $\mathrm{pH}$ - dependent equilibria that $\mathrm{Cr}(\mathrm{VI})$ may present when found in aqueous solutions and the interactions with solid adsorbent active groups should also be considered [3,21].

\section{Impact of DPB Dosage}

Although adsorption is a promising and versatile process for water and wastewater treatment, in some cases the high cost of adsorbents may be recognized as the biggest barrier to large scale applications. Thus, from economical point of view the optimization of adsorbent dosage and the best required mass of adsorbent for scale-up and designing of large scale equipment is necessary. Therefore, the dependence of $\mathrm{Cr}(\mathrm{VI})$ adsorption on the amount of $\mathrm{DPB}$ was studied at $\mathrm{pH} 6$ by varying the adsorbent amount from 0.25 to $10 \mathrm{~g} / \mathrm{L}$; the results regarding average adsorption capacity at various $\mathrm{Cr}(\mathrm{VI})$ concentrations $(50,100$ and $150 \mathrm{mg} / \mathrm{L}$ ) are presented in Fig. 5. The results indicate an decrease in the adsorption capacity of $\mathrm{Cr}(\mathrm{VI})$ with an increase in adsorbent dose until a minimum value was obtained. As depicted in Fig. 5, the trend for all $\mathrm{Cr}(\mathrm{VI})$ concentrations is the same and it be can divided into two stages: stage one from 0.25 to $1 \mathrm{~g} / \mathrm{L} \mathrm{DPB}$ dose ,and second stage more than $1 \mathrm{~g} / \mathrm{L}$ DPB dose.

For the first stage, improved removal adsorption (as the trend for all $\mathrm{Cr}(\mathrm{VI})$ concentration was similar; data was only shown for $\mathrm{Cr}(\mathrm{VI})$ concentration of $100 \mathrm{mg} / \mathrm{L}$ ) with an increase in DPB for all concentrations of $\mathrm{Cr}(\mathrm{VI})$ is due to an increase in the ratio of adsorbent to adsorbate, which increases the surface area and the number of sites available for adsorption [48]. Moreover, the highest rate of $\mathrm{Cr}(\mathrm{VI})$ adsorption in first stage can be attributed to availability of the free adsorption sites [1] and to a higher mass transfer

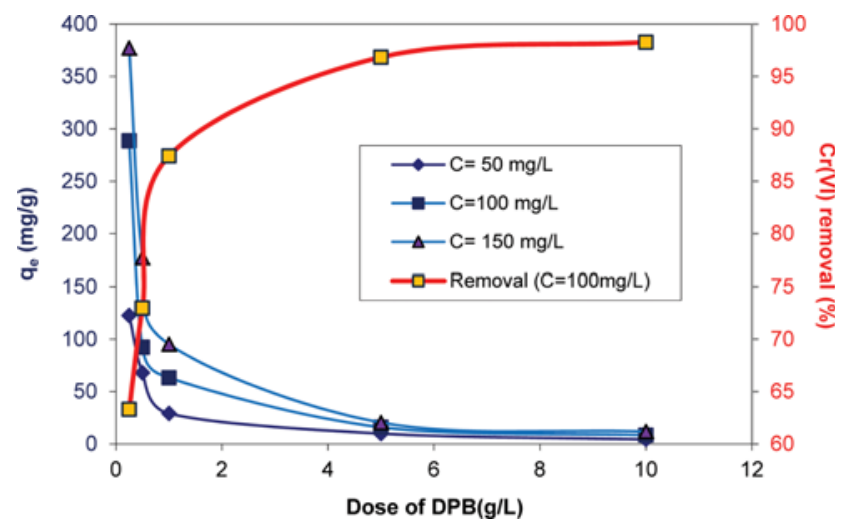

Fig. 5. Effects of DPB dose on adsorption capacity and $\mathrm{Cr}(\mathrm{VI})$ removal. rate. This result is supported by other studies (e.g., [49,50]). In stage two, the rate of $\mathrm{Cr}(\mathrm{VI})$ adsorbed to DPB (mg/g) did not significantly change with the increasing dosage of DPB. One plausible reason could be the overlap of active sites at higher DPB doses, resulting in reduced effective surface area required for adsorption [51].

Furthermore, Fig. 5 makes two important points. First, DPB possessed a higher adsorption capacity compared to most of the tested agricultural wastes (see Table 1), indicating that DPB is a promising low-cost adsorbent for $\mathrm{Cr}(\mathrm{VI})$ removal. Second, from an engineering and economic perspective, because DPB is profoundly available at low or no cost, a higher dosage should be used to reduce the size, operation and maintenance (mixing chamber), and the total cost of the treatment system.

\section{Impact of $\mathrm{Cr}(\mathrm{VI})$ Concentration}

The $\mathrm{Cr}(\mathrm{VI})$ in the effluent of different industries may have various concentrations, which raises the question of how different $\mathrm{Cr}(\mathrm{VI})$ concentrations influence the performance of the DPB for eliminating of chromium. The adsorption efficiency and capacity of 50, 100,150 , and $200 \mathrm{mg} / \mathrm{L} \mathrm{Cr}(\mathrm{VI})$ concentrations was studied for $2 \mathrm{~g} /$ $\mathrm{L}$ of DPB versus a contact time of up to $60 \mathrm{~min}$, and the means of the duplicate data are depicted in Fig. 6(a) and (b). Fig. 6(a) clearly shows a considerable effect of initial $\mathrm{Cr}(\mathrm{VI})$ concentration on its removal. Based on Fig. 6(a), the Cr(VI) removal was 90, 72.3, 66.1, and $55.2 \%$ for the fifth minute of mixing time for initial $\mathrm{Cr}(\mathrm{VI})$ concentrations of 50,100, 150 and $200 \mathrm{mg} / \mathrm{L}$, respectively. By increasing the mixing time to $60 \mathrm{~min}$, we obtained $100,97.3,92.2$, and $85.5 \%$ removal for $\mathrm{Cr}(\mathrm{VI})$ at the tested concentrations, respectively. Therefore, the reduction in $\mathrm{Cr}(\mathrm{VI})$ adsorption efficiency may be explained by the fact that the number of active adsorption sites
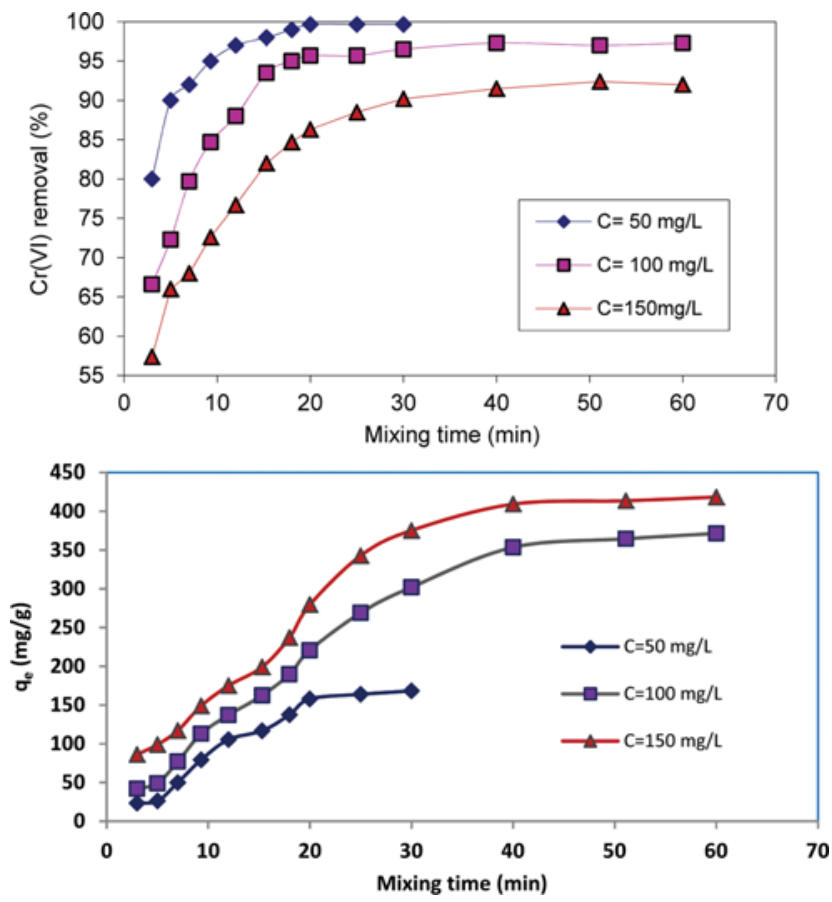

Fig. 6. Effects of $\mathrm{Cr}(\mathrm{VI})$ concentration on (upper) $\mathrm{Cr}(\mathrm{VI})$ removal by DPB and (downer) DPB adsorption capacity as a function of mixing time. 
to accommodate chromium ions remains constant, but with increasing chromium concentration the chromium ions to be accommodated increases and hence the removal efficiency of adsorption is reduced.

Fig. 6(b) indicates that the equilibrium adsorption capacity increases with increasing initial $\mathrm{Cr}(\mathrm{VI})$ concentration. When the initial $\mathrm{Cr}(\mathrm{VI})$ concentration increased from 50 to $200 \mathrm{mg} / \mathrm{L}$, the equilibrium adsorption capacity increased from 49.5 to $171 \mathrm{mg} / \mathrm{g}$. On the other hand, the adsorption capacity of $\mathrm{Cr}(\mathrm{VI})$ increased with an increase in initial ion concentration and contact time. This may be due to the increase in the number of $\mathrm{Cr}(\mathrm{VI})$ ions competing for the available binding sites in the surface of the adsorbent and a decrease in intraparticle diffusion as well as improved collisions between $\mathrm{Cr}(\mathrm{VI})$ ions and DPB particles [52,53]. Thus, these forces lead to the enhancement of $\mathrm{Cr}(\mathrm{VI})$ uptake by $\mathrm{DPB}$ particles. The high removal rates indicate a high affinity of DPB for $\mathrm{Cr}(\mathrm{VI})$ ions. These findings are in agreement with most previous studies examining the adsorption of $\mathrm{Cr}(\mathrm{VI})$ onto different adsorbents; however, the adsorption capacity of $\mathrm{Cr}(\mathrm{VI})$ (i.e., $171 \mathrm{mg} / \mathrm{g}$ ) much more than other researches indicated in Table 1. Overall, the rapid and efficient adsorption, consequence of abundancy of functional groups on the adsorbent surface, indicating a high affinity of DPB for $\mathrm{Cr}(\mathrm{VI})$ ions removal that make DPB a promising method for treating of water and wastewater containing $\mathrm{Cr}(\mathrm{VI})$.

\section{Impact of Co-existing Anions}

In natural water bodies and wastewaters, other anions may compete with $\mathrm{Cr}(\mathrm{VI})$ for adsorption sites, decreasing adsorbent removal efficiency. Fig. 7 shows the effect of co-existing ions $\mathrm{Cl}^{-}, \mathrm{NO}_{3}^{-}$, $\mathrm{SO}_{4}^{2-}, \mathrm{PO}_{4}^{3-}$, and $\mathrm{HCO}_{3}^{-}$on $\mathrm{Cr}(\mathrm{VI})$ adsorption by $\mathrm{DPB}$. The experiments, which were carried out as binary systems with fixed $\mathrm{Cr}(\mathrm{VI})$ ion concentration of $100 \mathrm{mg} / \mathrm{L} \cdot \mathrm{Cl}^{-}$and $\mathrm{NO}_{3}^{-}$, clearly have no significant impact on $\mathrm{Cr}(\mathrm{VI})$ adsorption as these ions $\left(\mathrm{Cl}^{-}\right.$and $\left.\mathrm{NO}_{3}^{-}\right)$ have low-affinity ligands [54]. When $\mathrm{PO}_{4}^{3-}$ and $\mathrm{SO}_{4}^{2-}$ existed in the system, there was a decrease in $\mathrm{Cr}(\mathrm{VI})$ adsorption from the aqueous solution. This may be due to the competition effect between the anions and chromate for the adsorption sites [55]. However, more decrease was observed in the presence of $\mathrm{HCO}_{3}^{-}$, which may be attributed to the enhancement of solution $\mathrm{pH}$ from 4 to 7.8 in addition to the competition between $\mathrm{HCO}_{3}^{-}$and chromate. Typical concentrations of $\mathrm{HCO}_{3}^{-}, \mathrm{SO}_{4}^{2-}$, and $\mathrm{PO}_{4}^{3-}$ in wastewater are much lower than the concentrations of other co-existing anions. As such, interference in most of the wastewaters would not be as strong as in this study.

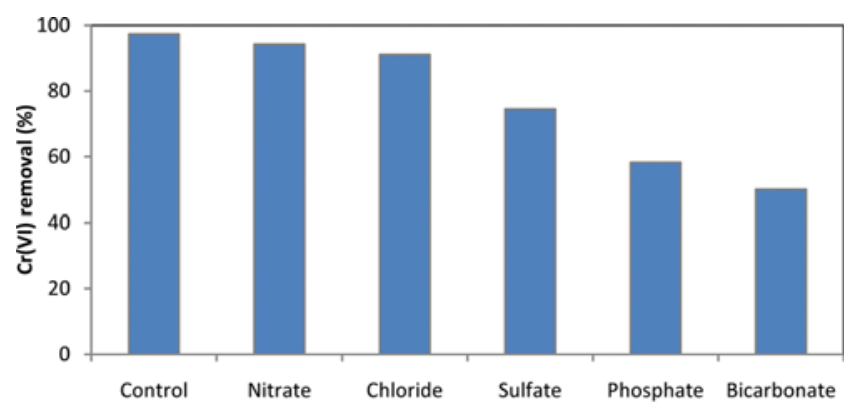

Fig. 7. Effects of co-existing anions on $\mathrm{Cr}(\mathrm{VI})$ removal.

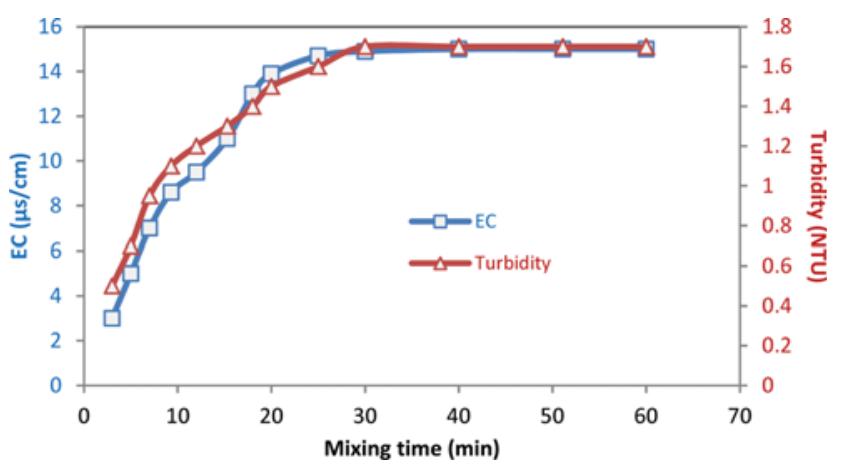

Fig. 8. Effects of the adsorbent on the conductivity (EC) and the Turbidity of treated effluent.

\section{Impact of DPB on Conductivity and Turbidity of Treated Solution}

Partial dissolution of adsorbent in the surrounding solution may have an impact on the adsorption process impacting ions uptake capacity. The rigidity of an adsorbent is a major aspect, and hence to assess for its stability in aqueous solution, the monitoring of conductivity (EC) and turbidity may be beneficial. A corresponding test was performed in double distilled water (Fig. 8). As seen, EC increased with time from 3 to $15 \mu \mathrm{s} / \mathrm{cm}$. This increase can be attributed to the presence of some soluble constituents from the adsorbents. Turbidity increased from 0.5 to 1.7 NTU. However, the increase in EC and turbidity at such values after $60 \mathrm{~min}$ contact time appeared very low if compared with EC and turbidity in actual wastewaters. The present adsorbent may therefore have only a slight impact on the conductivity and the turbidity of aqueous solutions.

\section{Reuse Test}

An important property of an adsorbent, from a practical point of view, is its reusability potential. To assess the reusability of the DPB in adsorption of $\mathrm{Cr}(\mathrm{VI})$, an experimental phase was carried out. The chromium removal efficiencies were monitored for four times recycling of DPB were 97.3, 82.9, 76.2, and 70.1\%, respectively. Thus, the DPB preserved its capability after four times recycling and the efficiency was still acceptable. Hence, DPB is an affordable and cost-benefit option for commercial purpose.

\section{Adsorption Modeling}

The successful representation of the dynamic adsorptive separation of solute from solution onto an adsorbent depends on a good description of the equilibrium separation between the two phases [45]. An adsorption isotherm is characterized by certain constant values, which describe the surface properties and affinity of the adsorbent and can also be used to compare the adsorptive capacities of the adsorbent for different pollutants [56]. Therefore, an isotherm would be informative for determining the maximum capacity of DPB for adsorbing $\mathrm{Cr}(\mathrm{VI})$ and useful for designing an optimized adsorption process. To describe the $\mathrm{Cr}(\mathrm{VI})$ uptake capacity and its adsorption behavior onto DPB, isotherm data obtained were fitted by four "two-parameter isotherm" including Langmuir, Freundlich, Dubinin-Radushkuvich (D-R), and Temkin.

The parameters of isotherms, $\mathrm{R}^{2}$ and RMSE for $\mathrm{Cr}(\mathrm{VI})$ adsorption onto DPB are listed in Table 4 . From Table 4 , a higher $\mathrm{R}^{2}$ (0.998) and a lower RMSE (2.76) were obtained in the Langmuir 
Table 4. Results of isotherm modeling for $\mathrm{Cr}(\mathrm{VI})$ adsorption on $\mathrm{DPB}$ at $24^{\circ} \mathrm{C}$

\begin{tabular}{lll}
\hline \hline Isotherm model & Parameters & Value \\
\hline \multirow{4}{*}{ Langmuir } & $\mathrm{K}_{L}$ & 0.0059 \\
& $\mathrm{Q}_{\text {max }}$ & 198.7 \\
& $\mathrm{R}_{L}$ & 0.53 \\
& $\mathrm{R}^{2}$ & 0.998 \\
& $\mathrm{RMSE}$ & 2.76 \\
\hline \multirow{5}{*}{ Freundlich } & $\mathrm{K}_{F}$ & 13.43 \\
& $1 / \mathrm{n}$ & 0.387 \\
& $\mathrm{R}^{2}$ & 0.968 \\
& $\mathrm{RMSE}$ & 7.85 \\
\hline \multirow{5}{*}{ Dubinin-Radushkevich } & $\mathrm{K}_{D R}$ & 0.0041 \\
& $\mathrm{q}_{m}$ & 85.39 \\
& $\mathrm{E}$ & 11.04 \\
& $\mathrm{R}^{2}$ & 0.964 \\
& $\mathrm{RMSE}$ & 6.98 \\
\hline \multirow{5}{*}{ Temkin } & $\mathrm{b}_{T}$ & 65.02 \\
& $\mathrm{k}_{T}$ & 14.03 \\
& $\mathrm{R}^{2}$ & 0.971 \\
& $\mathrm{RMSE}$ & 5.31 \\
\hline
\end{tabular}

model, suggesting that the Langmuir model fitted well to the data. Nevertheless, the value of RMSE in other studied models was greater than that in the Langmuir model, suggesting lower predicting accuracy with those models. Therefore, the Langmuir model reasonably fitted the experimental data. The Langmuir model is an empirical method for adsorbents with homogeneous adsorbing surfaces. Based on the Langmuir isotherm, maximum $\mathrm{Cr}(\mathrm{VI})$ adsorption capacity, $\mathrm{Q}_{m}$, of the tested DPB is $198.7 \mathrm{mg} / \mathrm{g}$. As shown in Table 4 , the $\mathrm{R}^{2}$ values of Langmuir model are 0.997 , which was highest value among all models. Previous research (see Table 1) has also shown that the adsorption of $\mathrm{Cr}(\mathrm{VI})$ onto DPB followed a typical Langmuir type isotherm. However, the $\mathrm{Q}_{m}$ value was satisfactorily greater than other studies. Feasibility of the $\mathrm{Cr}(\mathrm{VI})$ adsorption process on DPB was evaluated using a dimensionless constant separation factor or equilibrium parameter, $R_{L}$. The $R_{L}$ values are between 0 and 1; thus it can be concluded the adsorption of $\mathrm{Cr}(\mathrm{VI})$ on the tested DPB is favorable. Further, in the Freundlich model, the magnitude of the exponent, $1 / \mathrm{n}$, gives an indication of the favorability of adsorption [57]. A value of $1 / n=0.387$ represents a favorable adsorption condition, which proves that DPB is an appropriate and beneficial adsorbent for $\mathrm{Cr}(\mathrm{VI})$.

The D-R isotherm model was used to predict the nature of the adsorption process in terms of it being physical or chemical by calculating adsorption energy. The D-R isotherm relates the heterogeneity of energies close to an adsorbent surface. If a very small sub-region of the adsorption surface is considered and assumed to be approximate by the Langmuir isotherm, the quantity $1 / \sqrt{2 \mathrm{k}_{D R}}$ can be related to the mean adsorption energy, $\mathrm{E}$, which indicates information about the adsorption mechanism. Evaluations $\mathrm{E}<8 \mathrm{~kJ} /$ mol for an adsorption process determine a physical nature, and the range of $8-16 \mathrm{~kJ} / \mathrm{mol}$ determines a chemical nature $[1,58]$. The estimated value of $\mathrm{E}$ is demonstrated in Table 4; results show that chemisorption is the dominant mechanism of $\mathrm{Cr}(\mathrm{VI})$ adsorption onto DPB [59].

Table 4 depicts further that the experimental data had also a good correlation with the Temkin isotherm $\left(\mathrm{R}^{2}=0.949\right)$. Therefore, the adsorption of chromium ions by DPB is described by an even distribution of binding energies up to some maximum binding energy [60]. Also, the Temkin adsorption potential $\left(\mathrm{b}_{T} \ln \mathrm{k}_{T}\right)$ of DPB is $171.7 \mathrm{~kJ} / \mathrm{mol}$, illustrating that the bond between $\mathrm{Cr}(\mathrm{VI})$ ions and the DPB surface is very strong $[1,60]$. The Temkin constant, $b_{\mathfrak{T}}$ is defined as variation of adsorption energy, which indicates if the adsorption reaction is exothermic $\left(b_{T}>1\right)$ or endothermic $\left(b_{T}<1\right)$. The $b_{T}$ value was 65.02 , indicating that the adsorption reaction of $\mathrm{Cr}(\mathrm{VI})$ onto DPB occurs exothermically in the concentration range studied [61]. This fact suggests that there is an electrostatic interaction, and the heterogeneity of pores on DPB surface plays a significant role in $\mathrm{Cr}(\mathrm{VI})$ adsorption.

\section{Kinetics of $\mathrm{Cr}(\mathrm{VI})$ Adsorption onto DPB}

The time-concentration profile characteristics of the adsorption of $\mathrm{Cr}(\mathrm{VI})$ by DPB were analyzed by pseudo-first order, pseudo-second order, intraparticle diffusion (Weber-Morris), film diffusion (Boyd), Elovich, and Avrami kinetic models (Fig. 9(a)-(f)). In adsorption processes, the mechanism of adsorption (such as chemical reaction, diffusion control and mass transfer) was determined from kinetic models. The data from time-concentration profile was fitted onto abovementioned models, and the related parameters are collected in Table 5. A review of the available literature on the adsorption of $\mathrm{Cr}(\mathrm{VI})$ onto waste materials (Table 1) revealed that most researchers also reported that pseudo-second order models best fit experimental data. Our study confirms this finding. A comparison of the data obtained by the six models is given in Table 5 . The correlation coefficient $\left(\mathrm{R}^{2}\right)$ for the pseudo-first order model appears to be slightly lower than that for the pseudo-second order model, ranging from 0.992 to 0.995 . Furthermore, the $\mathrm{q}_{e, \text { exp }}$ values do not agree well with the calculated ones, and NSD values are also high. In contrast, for the pseudo-second order model the linear plot of $t / q_{t}$ vs $t$ presents (Fig. 9(b)) a very good fit with the experimental data with $\mathrm{R}^{2}$ close to 1 , indicating that the pseudo-second order model is more suitable for the adsorption of $\mathrm{Cr}(\mathrm{VI})$. The calculated $\mathrm{q}_{\mathrm{e}}$ values agree with the experimental data $\left(\mathrm{q}_{\mathrm{e} \text { exp }}\right)$ very well and NSD values were minimum among all studied models. The values of the $\mathrm{k}_{2}$ rate constant decrease with increasing initial concentration of $\mathrm{Cr}(\mathrm{VI})$, reflecting (a) the high competition for the adsorption surface sites at a high concentration, which leads to higher adsorption rates (b) the penetration of $\mathrm{Cr}(\mathrm{VI})$ ions onto internal part of adsorbent was slower than on the surface part.

The Elovich rate model equation is consistently used to study the kinetics of chemisorption of gasses on solids; however, some researchers have also applied this model to solid-liquid adsorption systems [54]. In the Elovich constant $\alpha$ is related to the adsorption rate and $\beta$ is related to the surface coverage. The as-obtained results are summarized in Table 5. The high $\mathrm{R}^{2}$ and low NSD values suggest that the experimental data also fit the Elovich model very well. A high positive correlation may indicate adequate $\mathrm{Cr}(\mathrm{VI})$ adsorption from the medium; $\beta$ values demonstrate the adsorbent ability to hold the $\mathrm{Cr}(\mathrm{VI})$ ions through chemisorption $[1,54]$. Because the 

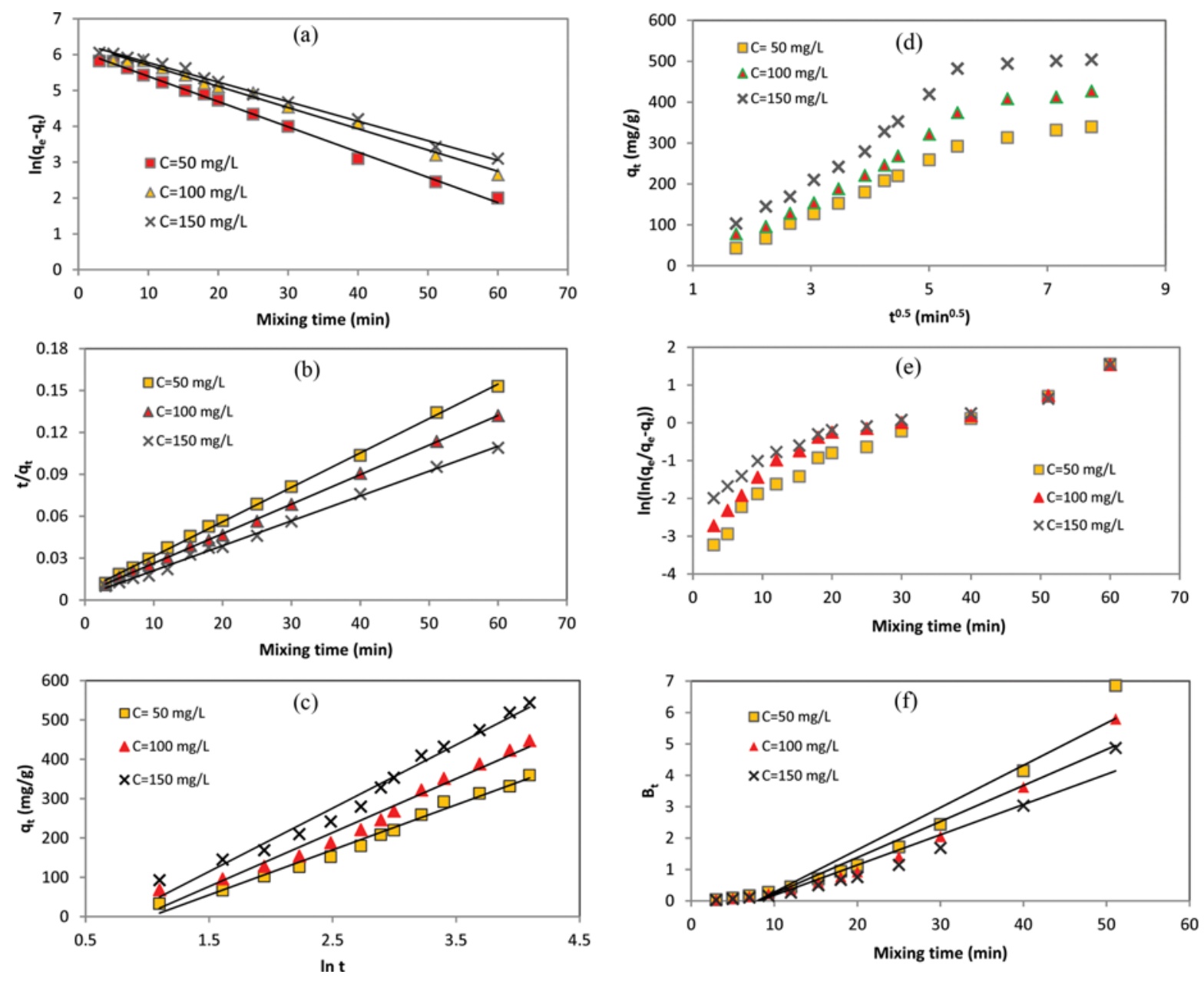

Fig. 9. The kinetic model of (a) pseudo-first order (b) pseudo-second order (c) Elovich model (d) intraparticle diffusion (Weber-Morris) model (e) Avrami model, and (f) film diffusion (Boyd) for adsorption of Cr(VI) onto DPB.

Table 5. Kinetic parameters for $\mathrm{Cr}(\mathrm{VI})$ adsorption on $\mathrm{DPB}$ at $24^{\circ} \mathrm{C}$

\begin{tabular}{|c|c|c|c|c|c|c|c|c|c|c|}
\hline \multirow{2}{*}{$\begin{array}{l}\text { Initial concentration } \\
\qquad(\mathrm{mg} / \mathrm{L})\end{array}$} & \multirow[b]{2}{*}{$\begin{array}{c}\mathrm{q}_{e, \exp } \\
(\mathrm{mg} / \mathrm{g})\end{array}$} & \multicolumn{4}{|c|}{ Pseudo-first-order kinetic model } & \multicolumn{5}{|c|}{ Pseudo-second-order kinetic model } \\
\hline & & $\begin{array}{c}\mathrm{q}_{e, \text { cal }} \\
(\mathrm{mg} / \mathrm{g})\end{array}$ & $\begin{array}{c}k_{1} \\
(1 / h)\end{array}$ & $\mathrm{R}^{2}$ & NSD & $\begin{array}{c}\mathrm{q}_{e, c a l} \\
(\mathrm{mg} / \mathrm{g})\end{array}$ & $\begin{array}{c}\mathrm{k}_{2} \\
(\mathrm{~g} / \mathrm{mg} \mathrm{h})\end{array}$ & $\mathrm{R}^{2}$ & NSD & - \\
\hline 50 & 76.26 & 35.5 & 0.53 & 0.995 & 15.3 & 64.2 & 0.027 & 0.999 & 3.58 & - \\
\hline 100 & 113.21 & 69.88 & 0.47 & 0.992 & 12.28 & 111.13 & 0.022 & 0.999 & 4.29 & - \\
\hline 150 & 179.46 & 111.43 & 0.49 & 0.994 & 10.49 & 173.91 & 0.0074 & 0.998 & 4.38 & - \\
\hline \multirow{2}{*}{$\begin{array}{l}\text { Initial concentration } \\
\qquad(\mathrm{mg} / \mathrm{L})\end{array}$} & \multirow{2}{*}{$\begin{array}{c}\mathrm{q}_{e, \exp } \\
(\mathrm{mg} / \mathrm{g})\end{array}$} & \multicolumn{4}{|c|}{ Intraparticle diffusion model } & \multicolumn{5}{|c|}{ Film diffusion (Boyd) model } \\
\hline & & $\begin{array}{c}\mathrm{q}_{e, \text { cal }} \\
(\mathrm{mg} / \mathrm{g})\end{array}$ & $\mathrm{k}_{i d}$ & $\mathrm{R}^{2}$ & NSD & $\begin{array}{c}\mathrm{q}_{e, c a l} \\
(\mathrm{mg} / \mathrm{g})\end{array}$ & $\mathrm{B}_{t}$ & $\mathrm{R}^{2}$ & NSD & - \\
\hline 50 & 76.26 & 59.54 & 0.16 & 0.977 & 6.17 & 85.5 & 0.53 & 0.933 & 35.5 & - \\
\hline 100 & 113.21 & 110.6 & 0.29 & 0.989 & 10.92 & 125.88 & 0.47 & 0.932 & 69.88 & - \\
\hline 150 & 179.46 & 169.61 & 0.47 & 0.989 & 9.26 & 171.83 & 0.49 & 0.929 & 111.43 & - \\
\hline \multirow{2}{*}{$\begin{array}{l}\text { Initial concentration } \\
\qquad(\mathrm{mg} / \mathrm{L})\end{array}$} & \multirow{2}{*}{$\begin{array}{c}\mathrm{q}_{e, \exp } \\
(\mathrm{mg} / \mathrm{g})\end{array}$} & \multicolumn{4}{|c|}{ Elovich model } & \multicolumn{5}{|c|}{ Avrami model } \\
\hline & & $\alpha$ & $\beta$ & $\mathrm{R}^{2}$ & NSD & $\begin{array}{c}\mathrm{q}_{e, c a l} \\
(\mathrm{mg} / \mathrm{g})\end{array}$ & $\mathrm{K}_{a v}$ & $\mathrm{n}_{a v}$ & $\mathrm{R}^{2}$ & NSD \\
\hline 50 & 76.26 & 11.61 & 0.56 & 0.986 & 2.57 & 60.52 & 0.28 & 0.28 & 0.926 & 11.45 \\
\hline 100 & 113.21 & 10.82 & 3.15 & 0.971 & 3.89 & 114.12 & 0.32 & 0.32 & 0.864 & 16.85 \\
\hline 150 & 179.46 & 3.41 & 1.68 & 0.977 & 5.98 & 162.91 & 0.31 & 0.31 & 0.904 & 9.43 \\
\hline
\end{tabular}


Physico-chemical study of dew melon peel biochar for chromium attenuation from simulated and actual wastewaters

Table 6. Thermodynamic parameters and adsorption energy for the adsorption of $\mathrm{Cr}$ (VI) onto DPB

\begin{tabular}{|c|c|c|c|c|c|c|}
\hline \multirow{2}{*}{$\begin{array}{c}\text { Adsorption energy } \\
(\mathrm{kJ} / \mathrm{mol})\end{array}$} & \multirow{2}{*}{ SP* } & \multirow{2}{*}{$\begin{array}{c}\Delta \mathrm{H}^{o} \\
(\mathrm{~kJ} / \mathrm{mol})\end{array}$} & \multirow{2}{*}{$\begin{array}{c}\Delta S^{o} \\
(\mathrm{~kJ} / \mathrm{mol} \mathrm{K})\end{array}$} & \multicolumn{3}{|c|}{ 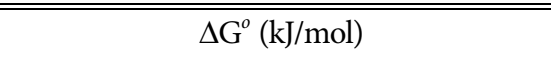 } \\
\hline & & & & $25^{\circ} \mathrm{C}$ & $35^{\circ} \mathrm{C}$ & $45^{\circ} \mathrm{C}$ \\
\hline 15.88 & 0.002 & 44.11 & 125 & -11.22 & -14.32 & -15.28 \\
\hline
\end{tabular}

Elovich model considers heterogeneous adsorptive sites, the $\mathrm{Cr}(\mathrm{VI})$ adsorption on the DPB may involve two or more interactions. Interactions may be mainly governed by electrostatic adsorption and hydrogen bonding mechanism [54]. The positive surface charge of DPB at the test conditions (solution $\mathrm{pH}<\mathrm{pH}_{z p c}$ ) attracts negatively charged $\mathrm{Cr}(\mathrm{VI})$ ions by means of electrostatic attraction; the positive surface attracts $\mathrm{Cr}(\mathrm{VI})$ by hydrogen bonding.

As shown in Table 5, the experimental data were fitted to WeberMorris model to evaluate whether intraparticle diffusion controlled the rate of $\mathrm{Cr}(\mathrm{VI})$ adsorption onto DPB. High values of $\mathrm{R}^{2}$ were obtained for all concentrations of $\mathrm{Cr}(\mathrm{VI})(50,100$, and 150 $\mathrm{mg} / \mathrm{L})$, suggesting that intraparticle diffusion was involved in the adsorption of chromium ions by DPB under the experimental conditions. However, the regression lines did not pass through the origin of the plot (see Fig. 9(d)) and a positive intercept was observed at all concentrations, indicating that another process was also involved in adsorption [62] of $\mathrm{Cr}(\mathrm{VI})$ onto DPB. Considering the concentration of $\mathrm{Cr}(\mathrm{VI})$ in solution, mass transfer of ions from boundary layer to adsorbent was not likely limiting the rate of adsorption. Therefore, both intraparticle diffusion and chemical adsorption were assumed to control the adsorption of $\mathrm{Cr}(\mathrm{VI})$ onto DPB under the experimental conditions. The low slope of the plots (Fig. 9(d)) indicates that adsorption approaches equilibrium in $40 \mathrm{~min}$, illustrating a high rate of $\mathrm{Cr}(\mathrm{VI})$ adsorption onto $\mathrm{DPB}$. The rate constants for intraparticle diffusion, $\mathrm{k}_{i d}$, obtained from the plots [3] are included in Table 5. The $\mathrm{k}_{i d}$ increased with an increase in $\mathrm{Cr}(\mathrm{VI})$ concentration, which validated the observed reduction in the pseudosecond order constant and the increase in the rate of adsorption as a function of adsorbate concentration. Moreover, the value of the intercept was increased with increasing the $\mathrm{Cr}(\mathrm{VI})$ concentration, indicating that chemisorption effects were more significant at higher ion concentrations.

The Avrami kinetic model had a good agreement with the experimental data, which was known from their high $\mathrm{R}^{2}$ and low NSD values (see Table 5). The applicability of Avrami kinetic model $\left(\mathrm{R}^{2}\right.$ : 0.864-0.926, NSD: 9.43-11.45) indicated that the mechanism of adsorption certainly followed multiple kinetic orders, which may change during the contact of the chromium ions with DPB.

The Boyd kinetic equation is useful for predicting the rate-limiting step involved in adsorption processes for different adsorbateadsorbent systems [61]. The Boyd plot (Fig. 9(f)) was obtained by plotting $\mathrm{B}_{t}$ versus $\mathrm{t}$ and can be used to identify if the rate-limiting step of adsorption is intraparticle diffusion or film diffusion. When the data points are linear and pass through the origin, there is evidence that intraparticle diffusion is the rate-limiting step of adsorption process. As can be seen in Fig. 9(f), the plots present some linearity, but not completely pass through the origin, attesting the involvement of film diffusion in the mechanism of adsorption [63]. Thus, according to the Boyd equation both mechanisms are possible.

\section{Thermodynamics Assessment}

To obtain an insight into the mechanism involved in the adsorption process, thermodynamic parameters including Gibbs free energy change $\left(\Delta \mathrm{G}^{o}\right)$, enthalpy change $\left(\Delta \mathrm{H}^{\circ}\right)$, and entropy change $\left(\Delta \mathrm{S}^{\circ}\right)$ were evaluated. Achieved thermodynamic parameters are presented in Table 6. The values of $\Delta G^{o}$ are negative, suggesting that the adsorption of $\mathrm{Cr}(\mathrm{VI})$ onto DPB was spontaneous and thermodynamically favorable. The change of Gibbs free energy decreased with increasing temperature, indicating higher adsorption efficiency at high temperatures. Moreover, the standard free energy change for multilayer adsorption was more than $-20 \mathrm{~kJ} / \mathrm{mol}$ and less than zero. It should be considered that the magnitude of $\Delta \mathrm{G}^{o}$ values is in the range of multilayer adsorption [45]. The positive values of $\Delta \mathrm{H}^{o}$ suggested that the adsorption process had an endothermic nature. Moreover, $\mathrm{Cr}(\mathrm{VI})$ uptake onto DPB was probably chemical because the magnitude of $\Delta \mathrm{H}^{o}$ was very close to the heat of a chemical reaction, which is more than $42 \mathrm{~kJ} / \mathrm{mol}$ [1]. Moreover, the positive value of $\Delta S^{o}$ indicated increased randomness at the solid/solution interface during the adsorption process, suggesting that $\mathrm{Cr}(\mathrm{VI})$ ions replaced some water molecules from the solution that had been previously adsorbed onto the surface of the adsorbent. These replaced water molecules had more translation entropy than was lost by the $\mathrm{Cr}(\mathrm{VI})$ ions, thus allowing for the prevalence of randomness in the system [1]. The value of SP* which was very close to zero confirmed the dominance of chemisorption mechanism [35]; therefore, the results of thermodynamic investigation reconfirmed the hypothesis of chemisorption of $\mathrm{Cr}(\mathrm{VI})$ ions onto DPB.

\section{Application to Electroplating and Tannery Industry Waste Effluent}

The effluent of two local industrial plants, electroplating and tannery, was treated by the adsorbent. The wastewater properties are given in Table 7. As presented in Table 7, removal values of 99.9 and $100 \%$ were obtained for electroplating and tannery wastewater, respectively. On the other hand, after $40 \mathrm{~min}$ mixing time the initial concentration of tannery and electroplating wastewater reached 0 and $0.04 \mathrm{mg} / \mathrm{L}$, respectively. Therefore, the US EPA standard, 0.05 $\mathrm{mg} / \mathrm{L}$, for the discharge of wastewater containing chromium into surface waters was met [64]. Thus, DPB is a potential and cost-effective adsorbent for the removal of $\mathrm{Cr}(\mathrm{VI})$ from industrial wastewaters.

\section{CONCLUSIONS}

A new biochar was prepared from dew melon peel by pyrolysis and used for the removal of $\mathrm{Cr}(\mathrm{VI})$ from simulated and actual wastewaters. The characterizations of dew melon peel biochar (DPB) were determined by various instrumental techniques such as, BET, SEM, FTIR, Boehm titration, and $\mathrm{pHzpc}$. The effects of $\mathrm{pH}$, initial $\mathrm{Cr}(\mathrm{VI})$ concentration, mixing time, coexisting ions competition, and reusability were investigated in batch experiments. The isotherm 
Table 7. Treatment of industrial wastewaters by DPB

\begin{tabular}{|c|c|c|c|}
\hline \multirow{2}{*}{ Sample } & \multirow{2}{*}{ Properties } & \multicolumn{2}{|c|}{ Value } \\
\hline & & Found & Treated \\
\hline \multirow{7}{*}{ Electroplating plant effluent } & $\mathrm{pH}$ & 5.2 (original) & 6.7 \\
\hline & TOC (mg/L) & 29 & 8 \\
\hline & TDS (mg/L) & 5601 & 5072 \\
\hline & Color & Dark green & Slightly green \\
\hline & $\mathrm{NH}_{4}^{+}(\mathrm{mg} / \mathrm{L})$ & 25.1 & 19.2 \\
\hline & $\mathrm{Ni}^{2+}(\mathrm{mg} / \mathrm{L})$ & 0.77 & 0.3 \\
\hline & $\mathrm{Cr}(\mathrm{VI})(\mathrm{mg} / \mathrm{L})$ & 36.6 & 0.04 \\
\hline \multirow{8}{*}{ Tannery plant effluent } & $\mathrm{pH}$ & 5.6 (original) & 6.9 \\
\hline & TOC (mg/L) & 47 & 11 \\
\hline & TDS (mg/L) & 2198 & 1902 \\
\hline & Color & Greenish yellow & Slightly yellow \\
\hline & $\mathrm{NH}_{4}^{+}(\mathrm{mg} / \mathrm{L})$ & 17.8 & 13.3 \\
\hline & $\mathrm{Ni}^{2+}(\mathrm{mg} / \mathrm{L})$ & 1.23 & 0.7 \\
\hline & $\mathrm{Cr}(\mathrm{III})(\mathrm{mg} / \mathrm{L})$ & 21.5 & No detectable \\
\hline & $\mathrm{Cr}(\mathrm{VI})(\mathrm{mg} / \mathrm{L})$ & 5.4 & No detectable \\
\hline
\end{tabular}

and kinetic models best fitted to experimental data were Langmuir and pseudo-second order, respectively. Maximum $\mathrm{Cr}(\mathrm{VI})$ ions adsorption by DPB was achieved $198.7 \mathrm{mg} / \mathrm{g}$. Two real wastewaters were successfully treated by DPB. The prepared DPB can be used for removing $\mathrm{Cr}(\mathrm{VI})$ ions from wastewaters with high reusability.

\section{ACKNOWLEDGEMENTS}

The authors are grateful for the technical support provided by Bushehr University of Medical Sciences, Bushehr, Iran. We are also thankful to Mr. H. Gorji from HSE Dept., Ministry of Industries and Business, Iran for collaboration in sampling of industrial wastewaters.

\section{REFERENCES}

1. G. Asgari, B. Ramavandi, L. Rasuli and M. Ahmadi, Desal. Water Treat., 51, 6009 (2013).

2. L. Giraldo-Gutiérrez and J. C. Moreno-Piraján, J. Anal. Appl. Pyrol., 81, 278 (2008).

3. G. Moussavi and B. Barikbin, Chem. Eng. J., 162, 893 (2010).

4. H. Deveci and Y. Kar, J. Ind. Eng. Chem., 19, 190 (2013).

5. R. Kumar, M. Ehsan and M. A. Barakat, J. Ind. Eng. Chem., 20, 4202 (2014).

6. H. Gao, Y. Liu, G. Zeng, W. Xu, T. Li and W. Xia, J. Hazard. Mater., 150, 446 (2008).

7. E. Malkoc and Y. Nuhoglu, Chem. Eng. Process., 46, 1020 (2007).

8. S. S. Hamdan and M. H. El-Naas, J. Ind. Eng. Chem., 20, 2775 (2014).

9. V. K. Gupta, A. Rastogi and A. Nayak, J. Colloid Interface Sci., 342, 135 (2010).

10. P. K. Ghosh, J. Hazard. Mater., 171, 116 (2009).

11. F. Di Natale, A. Erto, A. Lancia and D. Musmarra, J. Hazard. Mater., 281, 47 (2015).

12. J. R. Memon, S. Q. Memon, M. I. Bhanger, A. El-Turki, K. R. Hal- lam and G. C. Allen, Colloids Surf., B, 70, 232 (2009).

13. F. N. Acar and E. Malkoc, Bioresour. Technol., 94, 13 (2004).

14. K. M. Sumathi, S. Mahimairaja and R. Naidu, Bioresour. Technol., 96, 309 (2005).

15. E. A. Oliveira, S. F. Montanher, A. D. Andrade, J. A. Nóbrega and M. C. Rollemberg, Process Biochem., 40, 3485 (2005).

16. G. S. Agarwal, H. K. Bhuptawat and S. Chaudhari, Bioresour. Technol., 97, 949 (2006).

17. R. Elangovan, L. Philip and K. Chandraraj, Chem. Eng. J., 141, 99 (2008).

18. S. Basha, Z. V. P. Murthy and B. Jha, Chem. Eng. J., 137, 480 (2008).

19. L. Levankumar, V. Muthukumaran and M. B. Gobinath, J. Hazard. Mater., 161, 709 (2009).

20. R. Chand, K. Narimura, H. Kawakita, K. Ohto, T. Watari and K. Inoue, J. Hazard. Mater., 163, 245 (2009).

21. N. Tewari, P. Vasudevan and B. K. Guha, Biochem. Eng. J., 23, 185 (2005).

22. S. Gupta and B. V. Babu, J. Environ. Manag., 90, 3013 (2009).

23. N. H. Mthombeni, M.S. Onyango and O. Aoyi, J. Taiwan Inst. Chem. Eng., (In Press).

24. Y. Sun, Q. Yue, B. Gao, Y. Gao, Q. Li and Y. Wang, Chem. Eng. J., 217, 240 (2013).

25. Y. Bulut and Z. Tez, J. Environ. Sci., 19, 160 (2007).

26. D. Sud, G. Mahajan and M. P. Kaur, Biores. Technol., 99, 6017 (2008).

27. A. B. P. Marín, J. F. Ortuño, M. I. Aguilar, V.F. Meseguer, J. Sáez and M. Lloréns, Biochem. Eng. J., 53, 2 (2010).

28. A. H. El-Sheikh, M. M. Abu Hilal and J. A. Sweileh, Bioresour. Technol., 102, 5749 (2011).

29. C. R. Tarley and M. A. Arruda, Chemosphere, 54, 987 (2004).

30. H. Ucun, Y. K. Bayhan and Y. Kaya, J. Hazard. Mater., 153, 52 (2008).

31. K. M. Sreenivas, M. B. Inarkar, S. V. Gokhale and S. S. Lele, J. Environ. Chem. Eng., 2, 455 (2014).

32. G. Blázquez, F. Hernáinz, M. Calero, M. A. Martín-Lara and G. 
Tenorio, Chem. Eng. J., 148, 473 (2009).

33. G. E. Lester and D. M. Hodges, Postharvest Biol. Technol., 48, 347 (2008).

34. M. E. Saltveit, in Postharvest Biology and Technology of Tropical and Subtropical Fruits, Ed. E. M. Yahia, Woodhead Publishing, 31 (2011).

35. B. Ramavandi, Water Res. Ind., 6, 36 (2014).

36. G. Asgari, B. Ramavandi and S. Farjadfard, ScientificWorldJournal, 2013, 1 (2013).

37. B. Ramavandi, G. Asgari, J. Faradmal, S. Sahebi and B. Roshani, Korean J. Chem. Eng., 31, 2207 (2014).

38. A. D. Eaton, M. A. H. Franson, A. P. H. Association, A. W. W. Association and W.E. Federation, Standard Methods for the Examination of Water \& Wastewater, American Public Health Association (2005).

39. S. C. Ponce, C. Prado, E. Pagano, F. E. Prado and M. Rosa, Ecol. Eng., 74, 33 (2015).

40. S. Dahbi, M. Azzi and M. de la Guardia, Fresenius J. Anal. Chem., 363, 404 (1999).

41. M. W. I. Schmidt and A. G. Noack, Glob. Biogeochem. Cy., 14, 777 (2000).

42. W. A. W. A. K. Ghani, A. Mohd, G. da Silva, R. T. Bachmann, Y. H. Taufiq-Yap, U. Rashid and A. a. H. Al-Muhtaseb, Ind. Crop. Product, 44, 18 (2013).

43. M. I. Al-Wabel, A. Al-Omran, A. H. El-Naggar, M. Nadeem and A. R. A. Usman, Biores. Technol., 131, 374 (2013).

44. E. Broderick, H. Lyons, T. Pembroke, H. Byrne, B. Murray and M. Hall, J. Colloid Interface Sci., 298, 154 (2006).

45. J. H. Chen, H. T. Xing, H. X. Guo, G. P. Li, W. Weng and S. R. Hu, J. Hazard. Mater., 248-249, 285 (2013).

46. J. Samuel, M. Pulimi, M. L. Paul, A. Maurya, N. Chandrasekaran and A. Mukherjee, Bioresour. Technol., 128, 423 (2013).

47. H. Fida, S. Guo and G. Zhang, J. Colloid Interface Sci., 442, 30 (2015).
48. M. Bansal, D. Singh and V.K. Garg, J. Hazard. Mater., 171, 83 (2009).

49. M. Bansal, U. Garg, D. Singh and V. K. Garg, J. Hazard. Mater., 162, 312 (2009).

50. X. S. Wang, Z. Z. Li and S. R. Tao, J. Environ. Manage., 90, 721 (2009).

51. M. Rao, A. V. Parwate and A. G. Bhole, Waste Manage., 22, 821 (2002).

52. L.-H. Wang and C.-I. Lin, J. Taiwan Inst. Chem. Eng., 40, 110 (2009).

53. F. Bouhamed, Z. Elouear and J. Bouzid, J. Taiwan Inst. Chem. Eng., 43, 741 (2012).

54. Z. Wan, W. Chen, C. Liu, Y. Liu and C. Dong, J. Colloid Interface Sci., 443, 115 (2015).

55. R. Karthik and S. Meenakshi, Inter. J. Biol. Macromol., 72, 711 (2015).

56. J.H. Chen, G. P. Li, Q. L. Liu, J.C. Ni, W. B. Wu and J.M. Lin, Chem. Eng. J., 165, 465 (2010).

57. G. Asgari, B. Ramavandi and S. Sahebi, Desal. Water Treat., 52, 7354 (2013).

58. Y.-M. Chang, W.-T. Tsai and M.-H. Li, J. Anal. Appl. Pyrol., 111, 88 (2015).

59. M. N. Sepehr, A. Amrane, K. A. Karimaian, M. Zarrabi and H. R. Ghaffari, J. Taiwan Inst. Chem. Eng., 45, 635 (2014).

60. G. Moussavi and R. Khosravi, J. Hazard. Mater., 183, 724 (2010).

61. A. C. Martins, O. Pezoti, A. L. Cazetta, K. C. Bedin, D. A. S. Yamazaki, G. F. G. Bandoch, T. Asefa, J. V. Visentainer and V.C. Almeida, Chem. Eng. J., 260, 291 (2015).

62. F.-C. Wu, R.-L. Tseng and R.-S. Juang, J. Colloid Interface Sci., 283, 49 (2005).

63. B. H. Hameed, I. A. W. Tan and A. L. Ahmad, Chem. Eng. J., 144, 235 (2008).

64. A. Baral and R. D. Engelken, Environ. Sci. Policy, 5, 121 (2002). 